\title{
Bioaccumulation of Trace Metals in Wastewater-Fed Aquaculture: A Case Study in Turkey
}

\author{
Aslıhan Katip* \\ Bursa Uludag University, Faculty of Engineering, Department of Environmental Engineering, \\ Görükle Campus, Bursa, Turkey
}

Received: 17 May 2018

Accepted: 24 September 2018

\begin{abstract}
This study investigated the suitability of wastewater from secondary treatment used in breeding fishes of Carassius gibelio species, and using this fish for human food. For this purpose, metals (Fe, $\mathrm{Mn}, \mathrm{Cu}, \mathrm{Ni}, \mathrm{Zn}, \mathrm{Cr}, \mathrm{Pb}, \mathrm{Cd}$, As and B) in treated effluent and muscle, gill and liver tissues of fish were examined seasonally. It was found that treated effluent was suitable for irrigation and partially available for aquaculture, and the concentrations in fish tissues were over standard values. The values in liver and gill were higher than muscles. The TF (transfer factor) values of all metals examined were observed as $>1$ in the three tissues and the metals caused bioaccumulation. Concentrations in muscles were found to be 10 to 1000 times higher than in water. Size order of TF and BCF (bio-concentration factor) values in eatable muscle tissue were the same and it was $\mathrm{Zn}>\mathrm{Fe}>\mathrm{Pb}>\mathrm{Cu}>\mathrm{Ni}>\mathrm{Cd}>\mathrm{As}>\mathrm{Cr}>\mathrm{Mn}>\mathrm{B}$. Concentration differences among the tissues for $\mathrm{As}, \mathrm{Cd}, \mathrm{Pb}, \mathrm{Ni}$ and $\mathrm{B}$ were not significant $(\mathrm{P}>0.05)$. Because the correlations between $\mathrm{Cd}, \mathrm{Mn}, \mathrm{Pb}$ and $\mathrm{Cu}$ concentrations in tissues and treated effluent were found to be statistically significant, the metals caused bioaccumulation because of treated effluent. HQ (hazard quotient) and $\mathrm{BCF}$ values of $\mathrm{Pb}$ in muscle had carcinogenic risk levels.
\end{abstract}

Keywords: bioaccumulation, trace metals, wastewater-fed aquaculture

\section{Introduction}

Globally, more people live in urban areas than in rural areas, with 54 percent of the world's population residing in urban areas in 2014. In 1950, 30 percent of the world's population was urban, and by 2050, 66 percent of the world's population is projected to be urban. Africa and Asia are urbanizing faster than the

*e-mail: aballi@uludag.edu.tr other regions and are projected to become 56 and 64 per cent urban, respectively, by 2050 . Urban population numbers and water use patterns mainly determine the management of water supply and wastewater disposal and thereby contribute to the ecological footprint of a city. For the reasons of population growth, urbanization and industrialization, serious water demand will be in Turkey and the world. In addition, it was forecasted that water demand in Turkey of $1586 \mathrm{~L} /$ person/day in 1997 will increase to $3375 \mathrm{~L} /$ person/day in 2030 [1].

Since domestic wastewater often intermixes with effluents from industries and agricultural runoff, 
multidimensional approaches have been made toward maximizing protein production through rational exploitation of available resources. Sewage-fed aquaculture is a unique system and has manifold advantages in developing countries acting as a major source of nutrients for crop farming and aquaculture, and it is economical for sustainable production and helps to combat environmental pollution. The subject of sewage-fed aquaculture is reviewed in terms of source, chemical nature, diversity pattern, recycling practices, production potential of aquaculture, environmental issues and safety measures for eco-friendly sustainable environmental management strategies [2]. Wastewater was used in agriculture and aquaculture in 10 countries of Latin America, North Africa, and west and southeast Asia [3]. The economic viability of an aquaculture system depends on many technical, social, and economic factors that are specific to a given area or country. However, if they facilitate more efficient excreta collection, they should lead to reductions in both environmental pollution and unsanitary disease, and augment food production. A cost-benefit analysis was made of the experimental culture of fish in the Quail Creek sewage lagoon system near Oklahoma City. Net return was estimated at $\$ 0.02 / 1,000$ gallons raw of sewage [4]. Besides, if sewage water is treated, its use in aquaculture has some health disadvantages because of its toxic chemicals and microbiological pollution. Especiall, heavy metals are potentially harmful to most organisms at some level of exposure and absorption. Some heavy metals (cobalt, copper, iron, manganese, and zinc) are essential in trace concentrations to many organisms for enzyme function and are less toxic than non-essential heavy metals (cadmium, lead, mercury), which are toxic at the lowest concentrations [5].

It was found that wastewater-fed aquaculture in some of these studies could be used for human and animal food [6-10]. The major freshwater fish species used in this area include Labeo rohita (rohu), Catla catla (catla), Cirrhinusmrigala (mrigal), Oreochromis mossambicus (tilapia), and C. carpio (common carp) [10], black bass (Micropterus salmoides), big head (Aristichthys nobilis), silver carp (Hypophthalmichthys molitrix), grass carp (Ctenopharyngodon idellus), tench (tinca tinca), kissing gouramy (Helostoma tem,nincko), silver barb (Puntius gonionotus), nilem carp (Osteochilus hasseltil) and giant gourami (Osphronemusg oramy)[4]. These species are warm-water fish of temperate origin and can survive year-round in climates with seasonally low temperatures [4].

In this study, trace metal concentrations in muscle, gill and liver tissues of the Carassius gibelio species fed with wastewater from Bursa Water and Sewage Administration East Treatment Place were investigated. In addition, their bioaccumulations and health risks (transfer factors - TF, bio-concentration factors $\mathrm{BCF}$ and Hazard quotient - HQ) were computed and evaluated by comparison with metal concentrations in wastewater. Carassius gibelio is a species that can keep up with all kinds of climate and environmental conditions. Also, overbreeding of this species occurred as a result of the wrong inoculates in the past years in Turkish inland waters [11], and these fish must be evaluated economically. For this reason, this species was investigated in this study.

The objectives of this study were to investigate the suitability of fish for human food consumption in terms of metals, to provide a basis for the development of a standard on the concentration of heavy metals in reclaimed water used for fish aquaculture, and to search the possibilities of technical improvement of the system in terms of more efficient sewage treatment. This study was performed with the different fish species in the Marmara region, where the transition climate between the Mediterranean and Continent is dissimilar from the studies done so far that have contributed to the international literature and was significant. Also, this study included useful and valuable information for evaluating potential health risks in wastewater recovery as aquaculture feeding water.

\section{Material and Methods}

\section{Study Locations}

The East Wastewater Treatment Plant occupies $250000 \mathrm{~m}^{2}$ in the Küçük Balıklı area and treats domestic wastewater of Bursa City East Basin. It appeals to a population equal to about 1550000 and the project volume of flow is $240000 \mathrm{~m}^{3} /$ day for 2017 and $320000 \mathrm{~m}^{3} /$ day for 2030 . Its discharge area is Deliçay Creek, which is in the Susurluk River Basin. According to sensitive and less sensitive water areas notification, the discharge place is normal water area. The process type is the five-stage Bardenpho, which is an advanced biological treatment method, and nitrogen and phosphorus removal is performed. There is not a chemical treatment established. The flow diagram of the East Wastewater Treatment Plant is given in Fig. 1 and the influent-effluent wastewater characteristic of Treatment Plant of 2011 and removal performance data are presented in Table 1.

Carassius gibelio-type fish grown in wastewater-fed ponds were caught seasonally and metal concentrations in muscles, gills and livers were examined.

\section{Sample Handling and Analysis of Water and Fish Tissues}

The samples were examined for the presence of 10 elements (Fe, Mn, Cu, Zn, Cr, Pb, Cd, Ni, As and B) that were widely found in contaminated water and fishes.

The water samples were taken by using an Aquacell P2-COMPACT portable composite sampler, then transferred to dark polyethylene (PE) bottles washed with $\mathrm{HNO}_{3}$ and deionized water [12]. All the samples were taken monthly in one year from January 2011 to 


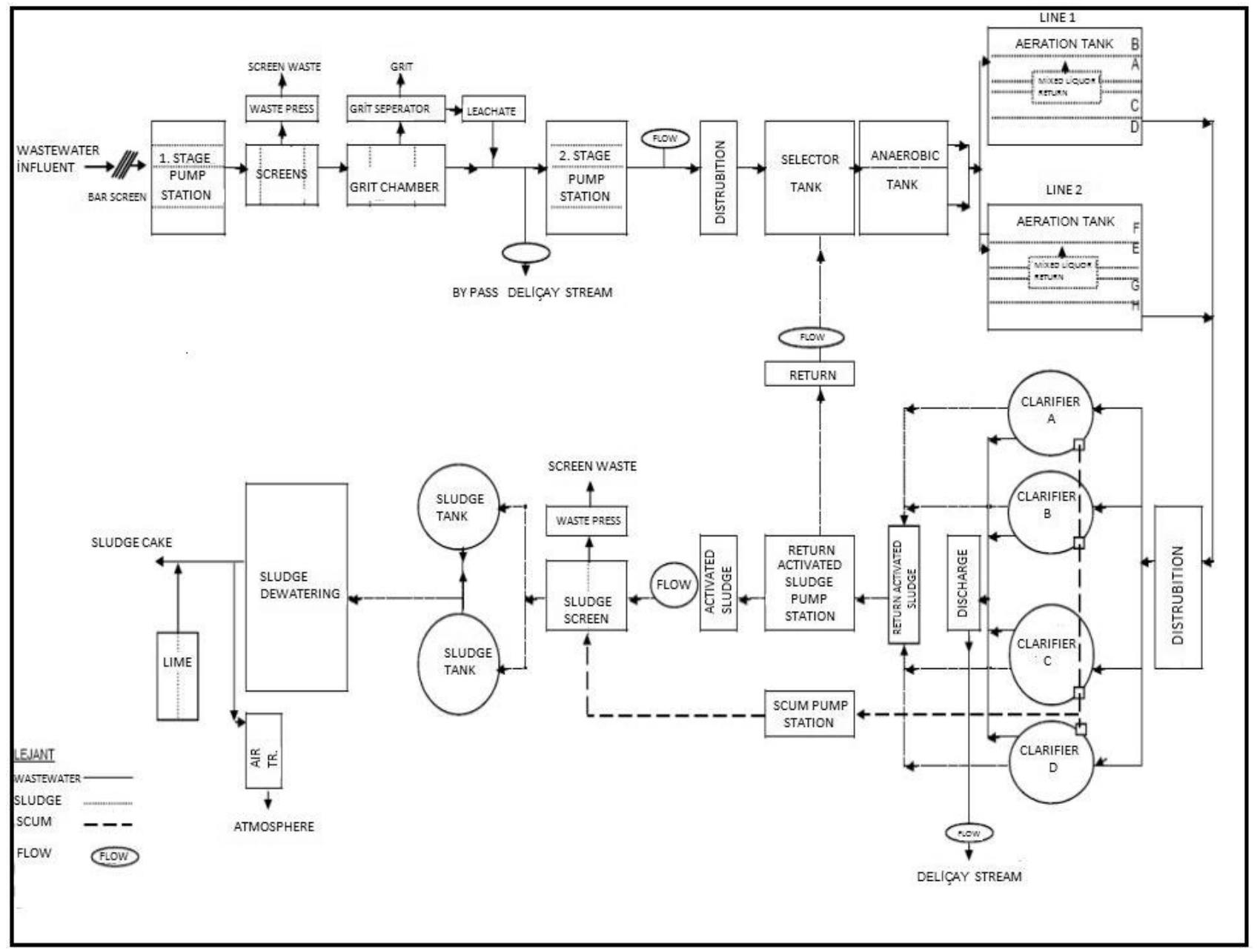

Fig. 1. Flow diagram of East Wastewater Treatment Plant.

2012 in order to see the seasonal changes. Water samples were filtered through a Milipore filter paper with preweighed $0.45 \mu \mathrm{m}$ pore-size. The filtered water samples were acidified with $0.2 \%(\mathrm{v} / \mathrm{v})$ concentrated nitric acid as for the precipitation samples and kept in glass bottles cleaned with detergent, water, nitric acid and Mili-Q water [13].

Twelve fish samples of Carassius gibelio specie were caught in the same year (2011-2012, 3 samples per season) from the fish breeding pool after the last clarifier.

Table 1. Influent-effluent wastewater characteristic of treatment plant (2011) and removal performance data.

\begin{tabular}{|c|c|c|c|c|c|c|c|c|c|c|c|c|c|c|c|c|c|c|}
\hline \multirow{2}{*}{ Seasons } & \multicolumn{7}{|c|}{ Influent } & \multicolumn{6}{|c|}{ Effluent } & \multicolumn{5}{|c|}{ Efficiency (\%) } \\
\hline & $\mathrm{pH}$ & $\mathrm{T}$ & AKM & BOI & KOI & $\mathrm{TP}$ & $\mathrm{TN}$ & $\mathrm{pH}$ & AKM & BOI & KOI & $\mathrm{TP}$ & $\mathrm{TN}$ & AKM & BOI & KOI & TP & $\mathrm{TN}$ \\
\hline Winter & 7.64 & 14.9 & 195 & 211 & 478 & 8.6 & 49 & .56 & 10.8 & 14 & 39 & 2.3 & 12.5 & 94 & 93 & 92 & 73 & 74 \\
\hline Spring & 7.71 & 16.7 & 169 & 185 & 410 & 7.8 & 48 & 7.56 & 10.2 & 14 & 37 & 2.1 & 11.2 & 94 & 92 & 91 & 73 & 77 \\
\hline Summer & 7.72 & 23.9 & 202 & 218 & 496 & 8.5 & 55 & 7.73 & 11.5 & 14 & 39 & 2.6 & 7.4 & 94 & 94 & 92 & 69 & 87 \\
\hline Autumn & 7.66 & 21.7 & 208 & 233 & 499 & 8.1 & 51 & 7.76 & 10.4 & 14 & 41 & 1.7 & 4.9 & 95 & 94 & 92 & 79 & 91 \\
\hline $\begin{array}{l}\text { Annual } \\
\text { Average }\end{array}$ & 7.68 & 19.3 & 193.5 & 211.8 & 470.8 & 8.25 & 50.8 & 7.65 & 10.73 & 14 & 39 & 2.18 & 9 & 94.3 & 93.3 & 91.8 & 73.5 & 82.3 \\
\hline Max & 7.72 & 23.9 & 208 & 233 & 499 & 8.6 & 55 & 7.76 & 11.5 & 14 & 41 & 2.6 & 12.5 & 95 & 94 & 92 & 79 & 91 \\
\hline Min & 7.64 & 14.9 & 169 & 185 & 410 & 7.8 & 48 & 7.56 & 10.2 & 14 & 37 & 1.7 & 4.9 & 94 & 92 & 91 & 69 & 74 \\
\hline $\begin{array}{c}\text { Std } \\
\text { Dev. }\end{array}$ & 0.04 & 4.24 & 17.18 & 20.06 & 41.55 & 0.37 & 3.1 & 0.11 & 0.573 & 0 & 1.63 & 0.38 & 3.49 & 0.5 & 0.96 & 0.5 & 4.12 & 8.06 \\
\hline
\end{tabular}


The fish were taken to a laboratory in polyethylene caps and their sizes were recorded. The fish were cut from their backing using a stainless steel knife, and muscle, liver, and gill tissues were removed. These tissues were then homogenized and $0.5 \mathrm{~g}$ (wet weight) were weighed and placed in constantly weighed petri dishes to dry for 24 hours in a drying oven. Afterward, the tissue samples fixed to dry weight were placed in temperatureand pressure-compensated HP500 Teflon caps. $7 \mathrm{ml}$ nitric acid $\left(\mathrm{HNO}_{3}\right)$ and $1 \mathrm{ml}$ hydrogen peroxide $\left(\mathrm{H}_{2} \mathrm{O}_{2}\right)$ were added as reagents and the samples were digested using a CEM Mars 5 Model microwave instrument [14]. Microwave decomposition operations were programmed as a 3-phase process. The device operated at 5 psi ( 1 psi $=6.89 \mathrm{kPa})$ for 1 minute in the $1^{\text {st }}$ stage, at 25 psi for 5 minutes in the $2^{\text {nd }}$ stage and at 120 psi for 60 minutes in the $3^{\text {rd }}$ stage [13]. After the samples were cooled to room temperature they were diluted to $50 \mathrm{ml}$ using ultra-pure water. The chemicals used in the digestion were analytically pure and ultra-pure water was used throughout the study [14]. For 10 years, microwave digestion systems have been used for sample extractions [15-17]. This technique is preferred because of its advantages such as rapid digestion, less contamination probability, and less acid consumption [16]. Blanks and European standard reference materials (ERMBB422) were included in each digestion batch to verify the accuracy of the calibration and standardization method, and all analyses were done in duplicate. The device was calibrated using a solution of $5 \mathrm{mg} \mathrm{L}^{-1}$ prepared from a Merck Mn solution of $500 \mathrm{mg} \mathrm{L}^{-1}$. An ambient temperature of $25^{\circ} \mathrm{C}$ was maintained to prevent possible expansion during calibration [13].

Heavy metals and trace elements in water and fish tissues were determined using the VISTA-MPX model of the VARIAN brand ICP-OES device. Also in water samples, dissolved oxygen (DO), temperature ( $\mathrm{T}$ ), $\mathrm{pH}$ and electrical conductivity (EC) parameters of water were measured using a HACH Sension 156 device [12]. Suspended solid matter (SS), biochemical oxygen demand $\left(\mathrm{BOD}_{5}\right)$ and chemical oxygen demand (COD) parameters were measured according to the standard methods [12]. Total nitrogen (TN) parameters were measured by water vapors distillation and, finally, total phosphorus (TP) was measured using the ascorbic acid method [12].

\section{Selection of the Fish Species}

In the last 100 years, intentional or unintentional entrance of invading fish species increased remarkably the destruction on aquatic habitats, and the success of these species over the world was been worrisome for all aquatic forms [18]. The Carrassius gibelio species that was assumed to be the most dangerous invading species by the Ministry of Agriculture was recorded in the harmful species with the $37 / 2$ numbered circular and sportive fishing, and it was unleashed during 12 months in Turkey [19]. In this research, this species that causes environmental pollution was studied in order to examine metal accumulation and to investigate the availability of the usage of this species for different purposes (e.g., food, bait etc.) and to make it beneficial for decreasing this species.

\section{Determining Metal Bioaccumulations and Statistical Analysis}

\section{Evaluating Metals in Fish and Wastewater}

Metal concentrations in the effluent wastewater of a treatment plant from which the fish was fed were compared with national and international toxic values for potable water, irrigation water, surface water and wastewater discharge standards [20-27]. Metal concentrations found in muscle, gill and liver tissues of fish samples were evaluated separately for dry and wet weight, and toxic levels were compared according to national and international standards [28-33].

\section{Metal Bioaccumulations and Risk Assessment}

The transfer and bio-concentration factors were calculated in order to determine metal bioaccumulation in fish tissues. The transfer factor in fish tissues from the aquatic ecosystem, which include water and sediments, was calculated according to Rashed (2001) [34] as follows:

$$
\begin{aligned}
\mathrm{TF}= & \mathrm{M}_{\text {tissue }}(\mathrm{mg} / \mathrm{kg} \text { dry weight }) / \\
& \mathrm{M}_{\text {sediment or water }}(\mathrm{mg} / \mathrm{L})
\end{aligned}
$$

and also bio-concentration factor as follows [35]:

$$
\mathrm{BCF}=\mathrm{M}_{\text {tissue }}(\mathrm{mg} / \mathrm{kg} \text { wet weight }) / \mathrm{M}_{\text {water }}(\mathrm{mg} / \mathrm{L})
$$

...where $\mathrm{M}_{\text {tissue }}$ is the metal concentration in fish tissue and $\mathrm{M}_{\text {sediment }}$ is metal concentration in sediment. The concentrations in TF sediments were not used in this study because only the effect of water was examined.

BCF is based on water-only exposures (lab data). $\mathrm{BCF}$ and $\mathrm{TF}$ are inversely related to exposure concentrations. $\mathrm{BCF}>1000$ and $\mathrm{TF}>1$ have been used to signify hazards in many national regulatory schemes. However, hazard and the potential for chronic effects cannot be just evaluated by magnitude of BCF [36]. $\mathrm{TF}, \mathrm{BCF}$ and standard concentration values should be evaluated together. $\mathrm{BCF}$ has different values for each metal [35].

The risk for human health as a result of eating Carassius gibelio was evaluated by calculating estimated daily intake (EDI) using the following equation [37, 38]:

$$
E D I=\frac{\mathrm{Cfish} * \mathrm{Dfish}}{B W}
$$


$\ldots$ where $\mathrm{C}_{\text {fish }}=$ the average trace element concentration in fish muscle ( $\mu \mathrm{g} / \mathrm{g}$ dry weight), $\mathrm{D}_{\text {fish }}=$ global average daily fish consumption (g/day) (which was only $1.7 \mathrm{~g} /$ day for Turkey) [39], and BW= average body weight $(\mathrm{kg})$.

U.S. EPA risk analysis considers an adult average body weight of $70 \mathrm{~kg}$ [40]. The hazard quotient (HQ) was calculated by dividing the estimated daily intake (EDI) by the established RfD (reference dose) to assess the health risk from fish consumption. There would be no obvious risk if the HQ were less than 1 [37].

\section{Statistical Analysis}

Statistical analysis of metals in treated effluent wastewater and fish tissues was performed. Correlation coefficients (r) determined the correlations between the parameters, and $\mathrm{p}$ values showed the significance levels and factorial ANOVA analysis carried out by using the general linear model method to be able to see if there were any variations in metal concentrations between tissues and seasons. The significance level was detected as $\mathrm{p} \leq 0.05$. Statistical calculations were done with a Minitab 17.0 Program [41]. The results were presented as the mean of triplicate determination.

\section{Results and Discussion}

\section{Metal Concentrations in Fishes and Treated Effluent Wastewater (TEW)}

Metal (Fe, $\mathrm{Mn}, \mathrm{Cu}, \mathrm{Ni}, \mathrm{Zn}, \mathrm{Cr}, \mathrm{Pb}, \mathrm{Cd}$, As and B) concentrations in muscle, gill and liver tissues of Carassius gibelio species were determined seasonally and their average values were compared with national and international standards. Concentrations were evaluated according to FAO [28, 30, 31, 38, 42], WHO [29], USFDA (U.S. Food and Drug Administration) [38, 43], TFC (Turkish Food Codecs) [33], England [32], the European Union (EU) [25] and Turkey [33] aquaculture standards.

The order of the metals according to their concentrations was: $\mathrm{Fe}>\mathrm{Zn}>\mathrm{B}>\mathrm{Pb}>\mathrm{Ni}>\mathrm{Mn}>\mathrm{Cu}>\mathrm{Cr}>$ $\mathrm{Cd}>$ As. According to FAO and WHO standards, it was found that $\mathrm{Mn}, \mathrm{Cr}, \mathrm{Pb}, \mathrm{Cd}$, and $\mathrm{Zn}$ were higher and $\mathrm{Cu}, \mathrm{Ni}, \mathrm{Fe}$ and $\mathrm{As}$ were lower. Different from the FAO and WHO values, according to English and Turkish standards $\mathrm{Mn}$ and $\mathrm{Zn}$ were found to be much lower. Metal concentrations in muscle tissues were compared with the results of other research examining Carassius gibelio and different fish species. As concentrations were found between the same and different fish species, $\mathrm{B}$ was found to be higher than other fish species. Fe and $\mathrm{Ni}$ were higher than Carassius gibelio, and lower than Cyprinus carpio in other research. $\mathrm{Zn}, \mathrm{Cr}$ and $\mathrm{Pb}$ were higher than Carassius gibelio and other species. Mn and $\mathrm{Cd}$ were in the range of concentrations of Carassius gibelio and higher than other species. $\mathrm{Cu}$ was in the concentration range determined for Carassius gibelio and lower than Cyprinus carpio.

The order of the metals in gill tissue according to their concentrations was: $\mathrm{Zn}>\mathrm{Fe}>\mathrm{Mn}>\mathrm{B}>\mathrm{Pb}>\mathrm{Ni}>\mathrm{Cu}>\mathrm{Cr}>\mathrm{Cd}>\mathrm{As}$. When the concentrations were compared with standard values, $\mathrm{Fe}, \mathrm{Mn}, \mathrm{Zn}, \mathrm{Cr}, \mathrm{Pb}, \mathrm{Cd}$ and $\mathrm{As}$ were found to be higher than FAO and WHO standards, but $\mathrm{Cu}$ and $\mathrm{Ni}$ were found to be lower than these standards. According to Turkish standards, Mn was lower as well, and other metals were the same as evaluating FAO and WHO standards. When it was compared with other research, $\mathrm{Fe}$ was found to be lower than other Carassius gibelio and Cyprinus carpio species. Mn was found to be lower than other Carassius gibelio and higher than Cyprinus carpio species. $\mathrm{Cu}$ and $\mathrm{As}$ were found in the range determined for Carassius gibelio species and lower than Cyprinus carpio species. $\mathrm{Zn}$ and $\mathrm{Ni}$ were higher than the concentrations of Carassius gibelio species, and lower than Cyprinus carpio. $\mathrm{Cr}, \mathrm{Pb}$ and $\mathrm{Cd}$ were higher than the values determined for other Carassius gibelio and Cyprinus carpio species. B was found to be higher than the concentrations found in other fish species.

The order of the trace elements in livers tissue according to their concentrations was: $\mathrm{Fe}>\mathrm{Zn}>\mathrm{B}>$ $\mathrm{Pb}>\mathrm{Cu}>\mathrm{Ni}>\mathrm{Mn}>\mathrm{Cr}>\mathrm{Cd}>\mathrm{As}$. According to $\mathrm{FAO}$ and WHO standards, $\mathrm{Fe}, \mathrm{Mn}, \mathrm{Zn}, \mathrm{Cr}, \mathrm{Pb}$ and $\mathrm{Cd}$ were found to be higher, and $\mathrm{Cu}, \mathrm{Ni}$, and $\mathrm{As}$ were found to be lower. While Mn, according to Turkish standards, and $\mathrm{Pb}$, according to English standards, were found to be lower, other metals were evaluated as the same as evaluating of FAO/WHO standards. When compared with other research, $\mathrm{Fe}, \mathrm{Cu}$ and $\mathrm{Cr}$ were in the range determined for Carassius gibelio, and higher than Cyprinus carpio and other species. Mn was in the concentration range determined for similar species - Carassius gibelio, and $\mathrm{Pb}$ and $\mathrm{Zn}$ were found to be higher than fish in both the same and different species. Cd was higher than the other concentrations of Carassius gibelio species, and in the range determined for other fish species. Ni was higher than the concentrations of Carassius gibelio species and lower than the other species. As was lower than the concentrations of the same species, and in the range of values determined for other species. B was found to be higher than other species [14, 44].

For B element there were no standard values found in regulations. Muscle, gill and livers were determined respectively as $8.525,8.388$ and $21.013 \mathrm{mg} \cdot \mathrm{kg}^{-1}(\mathrm{dw})$. As value was found for the limit value in each three tissues. Comparison of the metals found in muscle, gill and liver tissues and national-international standard values are presented in Tables 2-5.

The most harmful heavy metals investigated in this research were $\mathrm{Pb}$ and $\mathrm{Cd}$. These metals were hazardous in every concentration, they did not have biological functions and they were in the primary contaminant list [60]. The As, which was in the second group metals, was not biochemically necessary for the human body. Only its trace amounts could be tolerated. The third group of 
Table 2. Comparison of the metals found in muscle tissues and national-international standard values.

\begin{tabular}{|c|c|c|c|c|c|}
\hline Element & References & $\begin{array}{l}\text { Muscle } \\
\left(\mathrm{mg} \mathrm{kg}^{-1}\right)\end{array}$ & $\begin{array}{c}\text { FAO, 1983/ } \\
\text { WHO } \\
(\mathrm{dw} \mathrm{mg} \mathrm{kg-1)}\end{array}$ & $\begin{array}{c}\text { Turkish } \\
\text { Guidelines / } \\
\text { TFC } \\
\text { (ww mg kg-1 }{ }^{2} \text { ) }\end{array}$ & $\begin{array}{c}\text { England } \\
\left(\text { ww } \mathrm{mg} \mathrm{kg}^{-1}\right)\end{array}$ \\
\hline \multirow{5}{*}{$\mathrm{Fe}$} & $\begin{array}{c}\text { Özparlak, et al. } 2012 \text { (Beyşehir Lake, Carassius } \\
\text { gibelio, }(\mathrm{dw}) \text { ) [58] }\end{array}$ & $2.61 \pm 2.43$ & & & \\
\hline & $\begin{array}{c}\text { Köse and Uysal } 2008 \text { (Enne Dam Lake, Cyprinus } \\
\text { carpio,(ww)) [59] }\end{array}$ & $16.98 \pm 0.02$ & & & \\
\hline & $\begin{array}{l}\text { Milos`kovic', et al. } 2013 \text { (Gruža Reservoir, Serbia, } \\
\text { Carassius gibelio, }(\mathrm{dw} / \mathrm{ww})[60]\end{array}$ & $\begin{array}{l}18.1 \pm 9.65 / \\
7.53 \pm 4.02\end{array}$ & 100 & & \\
\hline & $\begin{array}{l}\text { Skoric, et al. } 2012 \text { (Ecka Fish Farm, Carassius gibelio, } \\
(\mathrm{dw}))[61]\end{array}$ & $48.47 \pm 10.43$ & & & \\
\hline & This study (ww / dw) & $\begin{array}{l}15.273 \pm 7.30 / \\
82.686 \pm 39.55\end{array}$ & & & \\
\hline \multirow{6}{*}{$\mathrm{Mn}$} & $\begin{array}{c}\text { Özparlak, et al. } 2012 \text { (Beyşehir Lake, Carassius } \\
\text { gibelio, }(\mathrm{dw}))[58]\end{array}$ & $9.34 \pm 0.36$ & & & \\
\hline & $\begin{array}{l}\text { Uysal and Atalay } 2007 \text { (DPÜ Lake, Cyprinus carpio, } \\
\text { (ww)) [62] }\end{array}$ & $0.14 \pm 0.05$ & & & \\
\hline & $\begin{array}{c}\text { Iraida et al. } 2012 \text { (Kadi Lake, Carassius auratus } \\
\text { gibelio, }(\text { ww) }[63]\end{array}$ & $0.64 \pm 1.174$ & & & \\
\hline & $\begin{array}{c}\text { Milos`kovic }{ }^{\prime} \text {, et al. } 2013 \text { (Gruža Reservoir, Serbia, } \\
\text { Carassius gibelio, }(\mathrm{dw} w w)[60]\end{array}$ & $\begin{array}{l}1.23 \pm 0.59 / \\
0.512 \pm 0.244\end{array}$ & 1 & 20 & \\
\hline & $\begin{array}{l}\text { Çiçek et. al. } 2009 \text { (Manyas Lake, Carassius gibelio, } \\
\text { (dw))[64] }\end{array}$ & $0.67 \pm 0.29$ & & & \\
\hline & This study (ww / dw) & $\begin{array}{c}0.855 \pm 1.316 / \\
4.628 \pm 7.123\end{array}$ & & & \\
\hline \multirow{7}{*}{$\mathrm{Cu}$} & $\begin{array}{c}\text { Çiçek et. al. } 2009 \text { (Manyas Lake, Carassius } \\
\text { gibelio, }(\mathrm{dw}))[64]\end{array}$ & $1.01 \pm 1.22$ & & & \\
\hline & $\begin{array}{l}\text { Ebrahimpour et al. } 2011 \text { (Anzali Wetland, Carassius } \\
\text { gibelio, }(\mathrm{dw}))[65]\end{array}$ & $7.4 \pm 1.1$ & & & \\
\hline & $\begin{array}{l}\text { Uysal and Atalay } 2007 \text { (DPÜ Göleti, Cyprinus } \\
\text { carpio (ww))[62] }\end{array}$ & $2.55 \pm 0.6$ & & & \\
\hline & $\begin{array}{c}\text { Wang et al, } 2014 \text { (Huainan Coal Fields, Carassius } \\
\text { Gibelio, }(\mathrm{dw}))[66]\end{array}$ & $1.14 \pm 0.22$ & 30 & 20 & 20 \\
\hline & $\begin{array}{l}\text { Milos`kovic', et al. } 2013 \text { (Gruža Reservoir, Serbia, } \\
\text { Carassius gibelio, (dw/ww)[60] }\end{array}$ & $\begin{array}{c}0.877 \pm 0.286 / \\
0.365 \pm 0.119\end{array}$ & & & \\
\hline & $\begin{array}{l}\text { Yabanli, et al. } 2013 \text { (Marmara Lake, Carassius gibelio, } \\
(\mathrm{dw}))[67]\end{array}$ & $0.60 \pm 1.32$ & & & \\
\hline & This study (ww / dw) & $\begin{array}{c}0.777 \pm 0.563 / \\
4.205 \pm 3.047\end{array}$ & & & \\
\hline \multirow{6}{*}{$\mathrm{Zn}$} & $\begin{array}{c}\text { Çiçek et. al. } 2009 \text { (Manyas Lake, Carassius gibelio, } \\
(\text { (dw))[64] }\end{array}$ & $33.86 \pm 8.70$ & & & \\
\hline & $\begin{array}{l}\text { Sapozhnikova et al. } 2005 \text { (Dniester River, C. auratus } \\
\text { gibelio, (ww))[68] }\end{array}$ & $6.90-9.95$ & & & \\
\hline & $\begin{array}{c}\text { Özparlak, et al. } 2012 \text { (Beyşehir Lake, Carassius } \\
\text { gibelio, }(\mathrm{dw}))[58]\end{array}$ & $13.98 \pm 2.70$ & & & \\
\hline & $\begin{array}{c}\text { Mazej et al. } 2010 \text { (Velenjsko jezero, Carassius } \\
\text { auratus gibelio, }(\mathrm{ww}))[69]\end{array}$ & 6.71 & $50 / 100$ & 50 & 50 \\
\hline & $\begin{array}{l}\text { Skoric, et al. } 2012 \text { (Ecka Fish Farm, Carassius gibelio, } \\
(\mathrm{dw}))[61]\end{array}$ & $46.39 \pm 16.12$ & & & \\
\hline & This study (ww / dw) & $\begin{array}{l}9.453 \pm 3.102 / \\
51.169 \pm 16.791\end{array}$ & & & \\
\hline
\end{tabular}


Table 2. Continued.

\begin{tabular}{|c|c|c|c|c|c|}
\hline \multirow{5}{*}{$\mathrm{Cr}$} & $\begin{array}{l}\text { Ebrahimpour et al. } 2011 \text { (Anzali Wetland, Carassius } \\
\text { gibelio, }(\mathrm{dw}))[65]\end{array}$ & $0.7 \pm 0.2$ & & & \\
\hline & $\begin{array}{l}\text { Çiçek et. al. } 2009 \text { (Manyas Lake, Carassius gibelio, } \\
(\text { (dw))[64] }\end{array}$ & $\begin{array}{l}<\text { Detection } \\
\text { Limit }\end{array}$ & & & \\
\hline & $\begin{array}{l}\text { Sapozhnikova et al. } 2005 \text { (Dniester River, C. auratus } \\
\text { gibelio, }(\mathrm{ww}))[68]\end{array}$ & 0.15 & 1 & & \\
\hline & $\begin{array}{l}\text { Yabanli, et al. } 2013 \text { (Marmara Lake, Carassius gibelio, } \\
\qquad(\mathrm{dw}))[67]\end{array}$ & $0.26 \pm 0.30$ & & & \\
\hline & This study (ww / dw) & $\begin{array}{c}0.420 \pm 0.399 / \\
2.273 \pm 2.159\end{array}$ & & & \\
\hline \multirow{6}{*}{$\mathrm{Pb}$} & $\begin{array}{l}\text { Çiçek, et al. } 2008 \text { (Uluabat Lake, Carassius gibelio } \\
(\mathrm{dw}))[70]\end{array}$ & $0.64 \pm 0.65$ & & & \\
\hline & $\begin{array}{l}\text { Mazej et al. } 2010 \text { (Velenjsko jezero, Cyprinus carpio, } \\
(\text { (ww))[69] }\end{array}$ & 0.01 & 0.5 & $1 / 0.3$ & 2 \\
\hline & $\begin{array}{l}\text { Ebrahimpour et al. } 2011 \text { (Anzali Wetland, Carassius } \\
\text { gibelio, }(\mathrm{dw}))[65]\end{array}$ & $1.3 \pm 0.5$ & & & \\
\hline & $\begin{array}{l}\text { Wang et al, } 2014 \text { (Huainan Coal Fields, Carassius } \\
\text { Gibelio, }(\mathrm{dw}))[66]\end{array}$ & $0.26 \pm 0.06$ & & & \\
\hline & $\begin{array}{l}\text { Milos`kovic', et al. } 2013 \text { (Gruža Reservoir, Serbia, } \\
\text { Carassius gibelio, (dw/ww)[60] }\end{array}$ & $\begin{array}{c}0.437 \pm 0.287 / \\
0.182 \pm 0.119 \\
\end{array}$ & & & \\
\hline & This study (ww / dw) & $\begin{array}{c}1.046 \pm 0.784 / \\
5.661 \pm 4.243\end{array}$ & & & \\
\hline
\end{tabular}

metals that were needed biochemically were $\mathrm{Fe}, \mathrm{Mn}, \mathrm{Cu}$, $\mathrm{Zn}, \mathrm{Ni}$, and $\mathrm{Cr}$. However, these metals might be toxic above a specific amount. These group elements like Ni, $\mathrm{Cr}$ and $\mathrm{Cu}$ were carcinogenic due to their interaction with nucleic acids [61]. In addition, heavy metals caused structural malfunctions and DNA breakage at the cellular and molecular level in aquacultures [62]. The reason for concentrations of $\mathrm{Fe}, \mathrm{Zn}, \mathrm{Mn}$ and $\mathrm{B}$ were found to be higher in order of magnitude is that they were essential elements.

When the metal concentrations in tissues were compared, it was seen that national and international

Table 3. Comparison of the metals found in gill tissues and national-international standard values.

\begin{tabular}{|c|c|c|c|c|c|}
\hline $\begin{array}{l}\text { Ele- } \\
\text { ments }\end{array}$ & References & $\begin{array}{c}\text { Gill } \\
\left(\mathrm{mg} \mathrm{kg}^{-1}\right)\end{array}$ & $\begin{array}{c}\text { FAO, 1983/ } \\
\text { WHO } \\
\left(\mathrm{dw} \mathrm{mg} \mathrm{kg}^{-1}\right)\end{array}$ & $\begin{array}{c}\text { Turkish } \\
\text { Guidelines / } \\
\text { TFC } \\
\text { (ww } \mathrm{mg} \mathrm{kg}^{-1} \text { ) }\end{array}$ & $\begin{array}{c}\text { England } \\
\left(\mathrm{ww} \mathrm{mg} \mathrm{kg}^{-1}\right)\end{array}$ \\
\hline \multirow{5}{*}{$\mathrm{Fe}$} & $\begin{array}{c}\text { Öztürk et. al. } 2009 \text { (Avşar Dam Lake, Cyprinus carpio, } \\
\text { (ww)) [71] }\end{array}$ & $203.7 \pm 106.9$ & & & \\
\hline & $\begin{array}{c}\text { Çiçek et. al. } 2009 \text { (Manyas Lake, Carassius gibelio, } \\
\text { (dw)) [64] }\end{array}$ & $913.75 \pm 360.27$ & & & \\
\hline & $\begin{array}{l}\text { Köse and Uysal } 2008 \text { (Enne Dam Lake, Cyprinus carpio, } \\
\text { (ww)) [59] }\end{array}$ & $87.19 \pm 11.88$ & 100 & & \\
\hline & $\begin{array}{l}\text { Skoric, et al. } 2012 \text { (Ecka Fish Farm, Carassius gibelio, } \\
(\mathrm{dw}))[61]\end{array}$ & $315.27 \pm 84.56$ & & & \\
\hline & This study (ww / dw) & $\begin{array}{r}54.322 \pm 20.051 / \\
287.309 \pm 106.049\end{array}$ & & & \\
\hline \multirow{4}{*}{$\mathrm{Mn}$} & $\begin{array}{l}\text { Uysal and Atalay } 2007 \text { (DPÜ Lake, Cyprinus carpio, } \\
\text { (ww)) [62] }\end{array}$ & $3.08 \pm 0.78$ & & & \\
\hline & $\begin{array}{c}\text { Çiçek et. al. } 2009 \text { (Manyas Lake, Carassius gibelio, } \\
\text { (dw)) [64] }\end{array}$ & $41.57 \pm 14.35$ & & & \\
\hline & $\begin{array}{l}\text { Skoric, et al. } 2012 \text { (Ecka Fish Farm, Carassius gibelio, } \\
(\mathrm{dw}))[61]\end{array}$ & $33.86 \pm 9.42$ & 1 & 20 & \\
\hline & This study (ww / dw) & $\begin{array}{l}4.088 \pm 1.410 / \\
21.621 \pm 7.404\end{array}$ & & & \\
\hline
\end{tabular}


Table 3. Continued.

\begin{tabular}{|c|c|c|c|c|c|}
\hline \multirow{6}{*}{$\mathrm{Cu}$} & $\begin{array}{l}\text { Ebrahimpour et al. } 2011 \text { (Anzali Wetland, Carassius } \\
\text { gibelio, }(\mathrm{dw}))[65]\end{array}$ & $11.9 \pm 4.1$ & & & \\
\hline & $\begin{array}{c}\text { Uysal and Atalay } 2007 \text { (DPÜ Lake, Cyprinus carpio, } \\
\text { (ww)) [62] }\end{array}$ & $3.815 \pm 0.12$ & & & \\
\hline & $\begin{array}{c}\text { Çiçek et. al. } 2009 \text { (Manyas Lake, Carassius gibelio,(dw)) } \\
{[64]}\end{array}$ & $2.26 \pm 1.16$ & & & \\
\hline & $\begin{array}{c}\text { Wang et al, } 2014 \text { (Huainan Coal Fields, Carassius } \\
\text { Gibelio, }(\mathrm{dw}))[66]\end{array}$ & $1.7 \pm 0.16$ & 30 & 20 & 20 \\
\hline & $\begin{array}{c}\text { Yabanli, et al. } 2013 \text { (Marmara Lake, Carassius gibelio, } \\
(\mathrm{dw}))[67]\end{array}$ & $0.72 \pm 1.36$ & & & \\
\hline & This study (ww / dw) & $\begin{array}{c}0.800 \pm 0.350 / \\
4.231 \pm 1.851\end{array}$ & & & \\
\hline \multirow{7}{*}{$\mathrm{Zn}$} & $\begin{array}{c}\text { Çiçek et. al. } 2009 \text { (Manyas Lake, Carassius gibelio, } \\
(\mathrm{dw}))[64]\end{array}$ & $191.89 \pm 29.67$ & & & \\
\hline & $\begin{array}{l}\text { Ebrahimpour et al. } 2011 \text { (Anzali Wetland, Carassius } \\
\text { gibelio, }(\mathrm{dw}))[65]\end{array}$ & $31.3 \pm 10$ & & & \\
\hline & $\begin{array}{c}\text { Mazej et al. } 2010 \text { (Velenjsko jezero, Carassius auratus } \\
\text { gibelio, }(\mathrm{ww}))[69]\end{array}$ & 58.6 & & & \\
\hline & $\begin{array}{l}\text { Uysal and Atalay } 2007 \text { (DPÜ Lake, Cyprinus carpio, } \\
\text { (ww)) [62] }\end{array}$ & $218.96 \pm 14.46$ & $50 / 100$ & 50 & 50 \\
\hline & $\begin{array}{c}\text { Wang et al, } 2014 \text { (Huainan Coal Fields, Carassius } \\
\text { Gibelio, (dw)) [66] }\end{array}$ & $14.44 \pm 0.75$ & & & \\
\hline & $\begin{array}{c}\text { Skoric, et al. } 2012 \text { (Ecka Fish Farm, Carassius gibelio, } \\
(\mathrm{dw}))[61]\end{array}$ & $286.11 \pm 103.65$ & & & \\
\hline & This study (ww / dw) & $\begin{array}{l}131.520 \pm 45.916 / \\
695.609 \pm 242.849\end{array}$ & & & \\
\hline \multirow{4}{*}{$\mathrm{Cr}$} & $\begin{array}{l}\text { Ebrahimpour et al. } 2011 \text { (Anzali Wetland, Carassius } \\
\text { gibelio, }(\mathrm{dw}))[65]\end{array}$ & $1.4 \pm 0.6$ & & & \\
\hline & $\begin{array}{l}\text { Uysal and Atalay } 2007 \text { (DPÜ Lake, Cyprinus carpio, } \\
\text { (ww)) [62] }\end{array}$ & $0.51 \pm 0.02$ & 1 & & \\
\hline & $\begin{array}{c}\text { Yabanli, et al. } 2013 \text { (Marmara Lake, Carassius gibelio, } \\
(\mathrm{dw}))[67]\end{array}$ & $0.32 \pm 0.33$ & & & \\
\hline & This study (ww / dw) & $\begin{array}{c}0.604 \pm 0.377 / \\
3.194 \pm 1.993\end{array}$ & & & \\
\hline \multirow{7}{*}{$\mathrm{Pb}$} & $\begin{array}{l}\text { Çiçek, et al. } 2008 \text { (Uluabat Lake, Carassius gibelio }(d w) \text { ) } \\
{[70]}\end{array}$ & $1.28 \pm 136$ & & & \\
\hline & $\begin{array}{c}\text { Çiçek et. al. } 2009 \text { (Manyas Lake, Carassius gibelio, } \\
\text { (dw)) [64] }\end{array}$ & $5.95 \pm 2.52$ & & & \\
\hline & $\begin{array}{l}\text { Ebrahimpour et al. } 2011 \text { (Anzali Wetland, Carassius } \\
\text { gibelio, }(\mathrm{dw}))[65]\end{array}$ & $3.1 \pm 1.6$ & & & \\
\hline & $\begin{array}{c}\text { Mazej et al. } 2010 \text { (Velenjsko jezero, Cyprinus carpio, } \\
(\text { (ww)) [69] }\end{array}$ & 0.06 & 0.5 & $1 / 0.3$ & 2 \\
\hline & $\begin{array}{c}\text { Mazej et al. } 2010 \text { (Velenjsko jezero, Carassius auratus } \\
\text { gibelio, }(\mathrm{ww}))[69]\end{array}$ & 0.48 & & & \\
\hline & $\begin{array}{c}\text { Yabanli, et al. } 2013 \text { (Marmara Lake, Carassius gibelio, } \\
(\mathrm{dw}))[67]\end{array}$ & $0.28 \pm 0.09$ & & & \\
\hline & This study (ww / dw) & $\begin{array}{c}1.481 \pm 0.628 / \\
7.833 \pm 3.321\end{array}$ & & & \\
\hline
\end{tabular}


Table 4. Comparison of the metals found in liver tissues and national-international standard values.

\begin{tabular}{|c|c|c|c|c|c|}
\hline $\begin{array}{l}\text { Ele- } \\
\text { ments }\end{array}$ & References & Liver $\left(m g ~ k g^{-1}\right)$ & $\begin{array}{c}\text { FAO, 1983/ } \\
\text { WHO } \\
\left(\mathrm{dw} \mathrm{mg} \mathrm{kg}{ }^{-1}\right)\end{array}$ & $\begin{array}{c}\text { Turkish } \\
\text { Guidelines / } \\
\text { TFC } \\
\text { (ww mg kg-1) }\end{array}$ & $\begin{array}{c}\text { England } \\
\left(\text { ww } \mathrm{mg} \mathrm{kg}^{-1}\right)\end{array}$ \\
\hline \multirow{4}{*}{$\mathrm{Fe}$} & $\begin{array}{c}\text { Öztürk et. al. } 2009 \text { (Avşar Dam Lake, Cyprinus carpio, } \\
\text { (ww)) [71] }\end{array}$ & $94.27 \pm 54.85$ & & & \\
\hline & $\begin{array}{l}\text { Çiçek et. al. } 2009 \text { (Manyas Lake, Carassius gibelio, } \\
(\text { (dw)) [64] }\end{array}$ & $<$ Detection Limit & 100 & & \\
\hline & $\begin{array}{l}\text { Skoric, et al. } 2012 \text { (Ecka Fish Farm, Carassius gibelio, } \\
(\mathrm{dw}))[61]\end{array}$ & $7926.08 \pm 4648.01$ & & & \\
\hline & This study (ww / dw) & $\begin{array}{l}202.25 \pm 153.018 / \\
1104.576 \pm 835.63\end{array}$ & & & \\
\hline \multirow{5}{*}{$\mathrm{Mn}$} & $\begin{array}{c}\text { Iraida et al. } 2012 \text { (Bol'shoi Ussuriiskii Island, C. aura- } \\
\text { tus gibelio, }(\mathrm{ww}))[63]\end{array}$ & $2.37 \pm 1.852$ & & & \\
\hline & $\begin{array}{c}\text { Iraida et al. } 2012 \text { (Sindinskaya Passage, Carassius } \\
\text { auratus gibelio, }(\mathrm{ww}) \text { ) }\end{array}$ & $9.22 \pm 8.121$ & & & \\
\hline & $\begin{array}{c}\text { Iraida et al. } 2012 \text { (Kadi Lake, Carassius auratus gibelio, } \\
\text { (ww)) }\end{array}$ & $0.64 \pm 0.266$ & 1 & 20 & \\
\hline & $\begin{array}{l}\text { Skoric, et al. } 2012 \text { (Ecka Fish Farm, Carassius gibelio, } \\
(\mathrm{dw}))[61]\end{array}$ & $8.13 \pm 5.98$ & & & \\
\hline & This study (ww / dw) & $\begin{array}{c}0.961 \pm 0.707 / \\
5.248 \pm 3.860\end{array}$ & & & \\
\hline \multirow{6}{*}{$\mathrm{Cu}$} & $\begin{array}{c}\text { Iraida et al. } 2012 \text { (Bol'shoi Ussuriiskii Island, C. aura- } \\
\text { tus gibelio, }(\mathrm{ww}) \text { ) [63] }\end{array}$ & $4.71 \pm 1.717$ & & & \\
\hline & $\begin{array}{l}\text { Ebrahimpour et al. } 2011 \text { (Anzali Wetland, Carassius } \\
\text { gibelio, }(\mathrm{dw}))[65]\end{array}$ & $20.5 \pm 3.8$ & & & \\
\hline & $\begin{array}{l}\text { Çiçek et. al. } 2009 \text { (Manyas Lake, Carassius } \\
\text { gibelio, }(\mathrm{dw}))[64]\end{array}$ & $8.34 \pm 5.76$ & 30 & 20 & 20 \\
\hline & $\begin{array}{l}\text { Skoric, et al. } 2012 \text { (Ecka Fish Farm, Carassius gibelio, } \\
(\mathrm{dw}))[61]\end{array}$ & $36.197 \pm 54.185$ & & & \\
\hline & $\begin{array}{l}\text { Yabanli, et al. } 2013 \text { (Marmara Lake, Carassius gibelio, } \\
(\mathrm{dw}))[67]\end{array}$ & $0.62 \pm 1.15$ & & & \\
\hline & This study (ww / dw) & $\begin{array}{c}1.270 \pm 0.683 / \\
6.935 \pm 3.729\end{array}$ & & & \\
\hline \multirow{5}{*}{$\mathrm{Zn}$} & $\begin{array}{c}\text { Çiçek et. al. } 2009 \text { (Manyas Lake, Carassius gibelio, } \\
(\mathrm{dw}))[64]\end{array}$ & $108.12 \pm 81.18$ & & & \\
\hline & $\begin{array}{l}\text { Ebrahimpour et al. } 2011 \text { (Anzali Wetland, Carassius } \\
\text { gibelio, }(\mathrm{dw}))[65]\end{array}$ & $27.4 \pm 3.0$ & & & \\
\hline & $\begin{array}{c}\text { Mazej et al. } 2010 \text { (Velenjsko jezero, Carassius auratus } \\
\text { gibelio, }(\mathrm{ww}))[69]\end{array}$ & 38.6 & $50 / 100$ & 50 & 50 \\
\hline & $\begin{array}{l}\text { Skoric, et al. } 2012 \text { (Ecka Fish Farm, Carassius gibelio, } \\
(\mathrm{dw}))[61]\end{array}$ & $119.96 \pm 129.65$ & & & \\
\hline & This study (ww / dw) & $\begin{array}{c}97.523 \pm 65.213 / \\
532.573 \pm 356.128\end{array}$ & & & \\
\hline \multirow{5}{*}{$\mathrm{Cr}$} & $\begin{array}{c}\text { Ebrahimpour et al. } 2011 \text { (Anzali Wetland, Carassius } \\
\text { gibelio, }(\mathrm{dw}))[65]\end{array}$ & $2.7 \pm 0.9$ & & & \\
\hline & $\begin{array}{c}\text { Öztürk et. al. } 2009 \text { (Avşar Dam Lake, Cyprinus carpio, } \\
(\text { ww)) [71] }\end{array}$ & $0.83 \pm 0.53$ & & & \\
\hline & $\begin{array}{l}\text { Çiçek et. al. } 2009 \text { (Manyas Lake, Carassius gibelio, } \\
\text { (dw)) [64] }\end{array}$ & $<$ Detection Limit & 1 & & \\
\hline & $\begin{array}{l}\text { Yabanli, et al. } 2013 \text { (Marmara Lake, Carassius gibelio, } \\
(\mathrm{dw}))[67]\end{array}$ & $0.36 \pm 0.33$ & & & \\
\hline & This study (ww / dw) & $\begin{array}{c}0.438 \pm 0.139 / \\
2.391 \pm 0.759\end{array}$ & & & \\
\hline
\end{tabular}


Table 4. Continued.

\begin{tabular}{|c|c|c|c|c|c|}
\hline \multirow{7}{*}{$\mathrm{Pb}$} & $\begin{array}{l}\text { Çiçek, et al. } 2008 \text { (Uluabat Lake, Carassius gibelio, } \\
\qquad(d w))[70]\end{array}$ & $8.1 \pm 18.52$ & & & \\
\hline & $\begin{array}{l}\text { Çiçek et. al. } 2009 \text { (Manyas Lake, Carassius gibelio, } \\
(\mathrm{dw}))[64]\end{array}$ & $0.55 \pm 0.96$ & & & \\
\hline & $\begin{array}{l}\text { Ebrahimpour et al. } 2011 \text { (Anzali Wetland, Carassius } \\
\text { gibelio, }(\mathrm{dw}) \text { ) [65] }\end{array}$ & $3.1 \pm 0.6$ & & & \\
\hline & $\begin{array}{l}\text { Mazej et al. } 2010 \text { (Velenjsko jezero, Cyprinus carpio, } \\
(\mathrm{ww}) \text { [69] }\end{array}$ & 0.06 & 0.5 & $1 / 0.3$ & 2 \\
\hline & $\begin{array}{c}\text { Mazej et al. } 2010 \text { (Velenjsko jezero, Carassius auratus } \\
\text { gibelio, (ww)) [69] }\end{array}$ & 0.05 & & & \\
\hline & $\begin{array}{l}\text { Yabanli, et al. } 2013 \text { (Marmara Lake, Carassius gibelio, } \\
(\mathrm{dw}))[67]\end{array}$ & $0.16 \pm 0.33$ & & & \\
\hline & This study (ww / dw) & $\begin{array}{c}1.613 \pm 0.839 / \\
8.808 \pm 4.581\end{array}$ & & & \\
\hline
\end{tabular}

limit values are different. Six of 10 metals examined conformed to national standards, but did not conform to international standards. For example, while $\mathrm{Mn}$ and $\mathrm{Cr}$ concentrations were found in each three tissue, in terms of wet weight, were under Turkish standard values, their concentrations, in terms of dry weight, were above international limit values. There was too much difference between standard values. The difference between concentration levels of countries and institutions, in terms of wet and dry weight, was also insignificant. Because of possible analysis mistakes stemming from moisture loss while determining concentrations in terms of wet weight, determining concentrations in terms of dry weight would help to

Table 5. Comparison of Cd, Ni, As and B elements found in muscle, gill and liver tissues and national-international standard values.

\begin{tabular}{|c|c|c|c|c|c|c|}
\hline $\begin{array}{l}\text { Ele- } \\
\text { ment }\end{array}$ & Tissues & References & $\begin{array}{l}\text { Concentration } \\
\left(\mathrm{mg} \mathrm{kg}^{-1}\right)\end{array}$ & $\begin{array}{c}\text { FAO, 1983/ } \\
\text { WHO } \\
(\mathrm{dw} \mathrm{mg} \mathrm{kg-1)}\end{array}$ & \begin{tabular}{|c|} 
Turkish \\
Guidelines / \\
TFC \\
$\left(\right.$ ww $\mathrm{mg} \mathrm{kg-}^{-1}$ ) \\
\end{tabular} & $\begin{array}{c}\text { England } \\
\left(\text { ww } \mathrm{mg} \mathrm{kg}^{-1}\right)\end{array}$ \\
\hline \multirow{12}{*}{$\mathrm{Cd}$} & \multirow{4}{*}{ Muscle } & $\begin{array}{c}\text { Ebrahimpour et al. } 2011 \text { (Anzali Wetland, } \\
\text { Carassius gibelio, }(\mathrm{dw}) \text { ) [65] }\end{array}$ & $0.29 \pm 0.19$ & & & \\
\hline & & $\begin{array}{c}\text { Özparlak, et al. } 2012 \text { (Beyşehir Lake, Carassius } \\
\text { gibelio },(\mathrm{dw}))[58]\end{array}$ & $2.29 \pm 0.06$ & & & \\
\hline & & $\begin{array}{c}\text { Sapozhnikova et al. } 2005 \text { (Dniester River, } C \text {. } \\
\text { auratus gibelio, }(\mathrm{ww}))[68]\end{array}$ & 0.04 & $0.5 / 1$ & $0.1 / 0.05$ & 0.2 \\
\hline & & This study (ww / dw) & $\begin{array}{c}0.229 \pm 0.264 / \\
1.239 \pm 1.429\end{array}$ & & & \\
\hline & \multirow{4}{*}{ Gill } & $\begin{array}{c}\text { Ebrahimpour et al. } 2011 \text { (Anzali Wetland, } \\
\text { Carassius gibelio, }(\mathrm{dw}))[65]\end{array}$ & $0.45 \pm 0.29$ & & & \\
\hline & & $\begin{array}{c}\text { Öztürk et al. } 2009 \text { (Avşar Dam Lake, Cyprinus } \\
\text { carpio, }(\mathrm{ww}))[71]\end{array}$ & $0.15 \pm 0.14$ & & & \\
\hline & & $\begin{array}{l}\text { Yabanli, et al. } 2013 \text { (Marmara Lake, Carassius } \\
\text { gibelio, }(\mathrm{dw}))[67]\end{array}$ & $0.03 \pm 0.02$ & & & \\
\hline & & This study (ww / dw) & $\begin{array}{c}0.248 \pm 0.306 / \\
1.311 \pm 1.618 \\
\end{array}$ & & & \\
\hline & \multirow{4}{*}{ Liver } & $\begin{array}{c}\text { Ebrahimpour et al. } 2011 \text { (Anzali Wetland, } \\
\text { Carassius gibelio, }(\mathrm{dw}))[65]\end{array}$ & $1.05 \pm 0.34$ & & & \\
\hline & & $\begin{array}{c}\text { Mazej et al. } 2010 \text { (Velenjsko jezero, Carassius } \\
\text { auratus gibelio, }(\mathrm{ww}))[69]\end{array}$ & 0.02 & & & \\
\hline & & $\begin{array}{c}\text { Öztürk et. al. } 2009 \text { (Avşar Dam Lake, Cyprinus } \\
\text { carpio, }(\mathrm{ww}))[71]\end{array}$ & $0.79 \pm 0.33$ & & & \\
\hline & & This study (ww / dw) & $\begin{array}{c}0.289 \pm 0.275 / \\
1.578 \pm 1.501\end{array}$ & & & \\
\hline
\end{tabular}


Table 5. Continued.

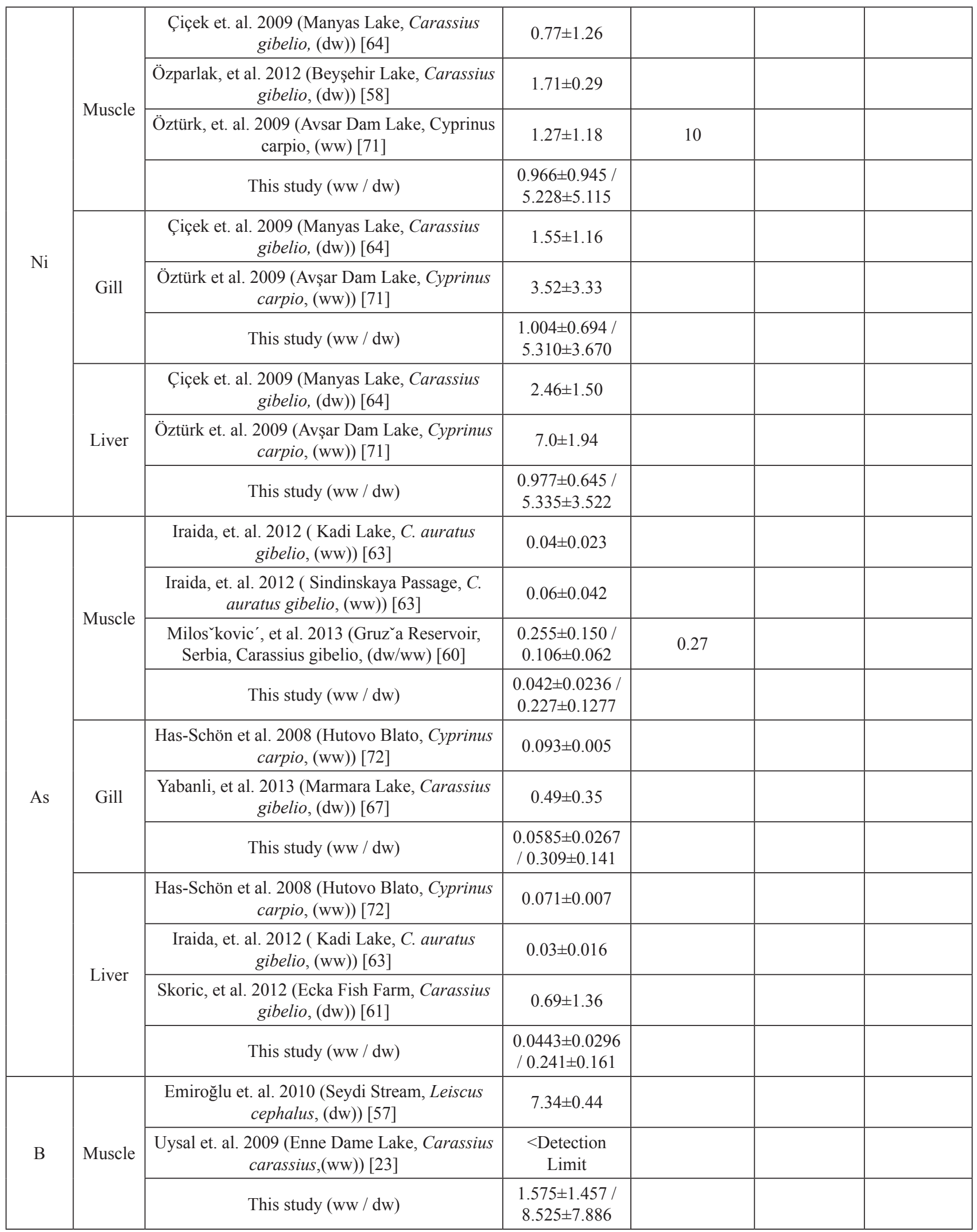

prevent evaluation mistakes. Since there were no guideline values or provisional limits for metal intake (g/day/body weight), the results obtained in this study could be used to derive such guideline values. However, this needs to be further examined in future studies [38]. Heavy metals not only influence living bodies depending on their concentrations. The influence depends on species of organisms and ionic structure 
Table 6. ANOVA concentration differences between tissues and months .

\begin{tabular}{|c|c|c|c|c|c|c|c|c|c|c|}
\hline & $\mathrm{As}$ & $\mathrm{Cr}$ & $\mathrm{Cd}$ & $\mathrm{Pb}$ & $\mathrm{Cu}$ & $\mathrm{Ni}$ & $\mathrm{B}$ & $\mathrm{Fe}$ & $\mathrm{Mn}$ & $\mathrm{Zn}$ \\
\hline P values (Tissue) & 0.207 & $\mathbf{0 . 0 1 5}$ & 0.829 & 0.123 & $\mathbf{0 . 0 2 7}$ & 0.979 & 0.159 & $\mathbf{0}$ & $\mathbf{0}$ & $\mathbf{0}$ \\
\hline P values (Months) & $\mathbf{0 . 0 1}$ & $\mathbf{0}$ & $\mathbf{0 . 0 0 8}$ & $\mathbf{0 . 0 2}$ & $\mathbf{0 . 0 0 3}$ & $\mathbf{0}$ & 0.496 & 0.117 & $\mathbf{0}$ & $\mathbf{0 . 0 2 5}$ \\
\hline
\end{tabular}

*Dark Colored $\mathrm{p}<0.05$

of metal (solubility value, chemical structure, redox and ability of forming complex), intake type to body, presence frequency in the environment and $\mathrm{pH}$ value of water. Therefore, the water used in aquaculture was limited by legal institutions with limit values and their control was an obligation [63].

The wastewater that the fish fed from TFE was evaluated by national and international regulations. According to this, it is determined that most of the metals were above the drinking water standards [24, 25, 27] and the USEPA's toxic evaluation values of surface water [26], $\mathrm{Zn}$ and $\mathrm{Cu}$ is not available according to Turkish Aquaculture Regulation [22], but other metals were available, and all metals were appropriate with the standards for Irrigation Water of Technical Methods Notification of Wastewater Treatment Plants [23]. In addition, according to Aquaculture Regulation of the People's Republic of China-GB 8978, all metals were determined as convenient except for $\mathrm{Cd}$ [21]. Annual average and standard deviation values of metals in treated feed wastewater (TFE) were presented in the chapter "Metal Bioaccumulations and Risk Assessment," according to which wastewater might be available for irrigation water and partially available for aquaculture.

\section{Statistical Analysis}

In order to determine whether the concentration difference between tissues and months were important or not, variance analysis and factorial ANOVA table with general linear method were made and calculated by using the Minitab 16 program [41]. Significance of the results was evaluated at a significance level of $p<0.05$.

In general, different heavy metal accumulation capacities were observed among different tissues. While the high metal concentrations were found in livers and gills, the lowest metal accumulation was observed in muscles. The high metal concentrations in the gills were the first target for pollutants that could be due to the formation of complex ions with mucus, which virtually could not be completely removed from the gill Lamellae before preparation for analysis [64]. Also, liver is a detoxification organ accumulating toxic elements. The reason for low levels of heavy metals could be the low levels of binding protein in muscles [38]. In Table 6, $p$ values of the ANOVA table, which were calculated for concentration differences between tissues and months, were presented.

According to the table, concentration differences between tissues for $\mathrm{Cr}, \mathrm{Cu}, \mathrm{Fe}, \mathrm{Mn}$ and $\mathrm{Zn}$ were significant $(\mathrm{p}<0.05)$, but the differences for $\mathrm{As}, \mathrm{Cd}, \mathrm{Pb}$, $\mathrm{Ni}$ and $\mathrm{B}$ elements in the tissues were not significant ( $\mathrm{p}>0.05$ ). According to annual concentration averages, the highest values for $\mathrm{Cr}, \mathrm{Mn}$ and $\mathrm{Zn}$ were found in gills and the highest values for $\mathrm{Cu}$ and $\mathrm{Fe}$ were found in livers. The metal concentration differences among the months were examined significantly $(\mathrm{p}<0.05)$, except for $\mathrm{B}$ and $\mathrm{Fe}$. When the concentrations in all tissues were
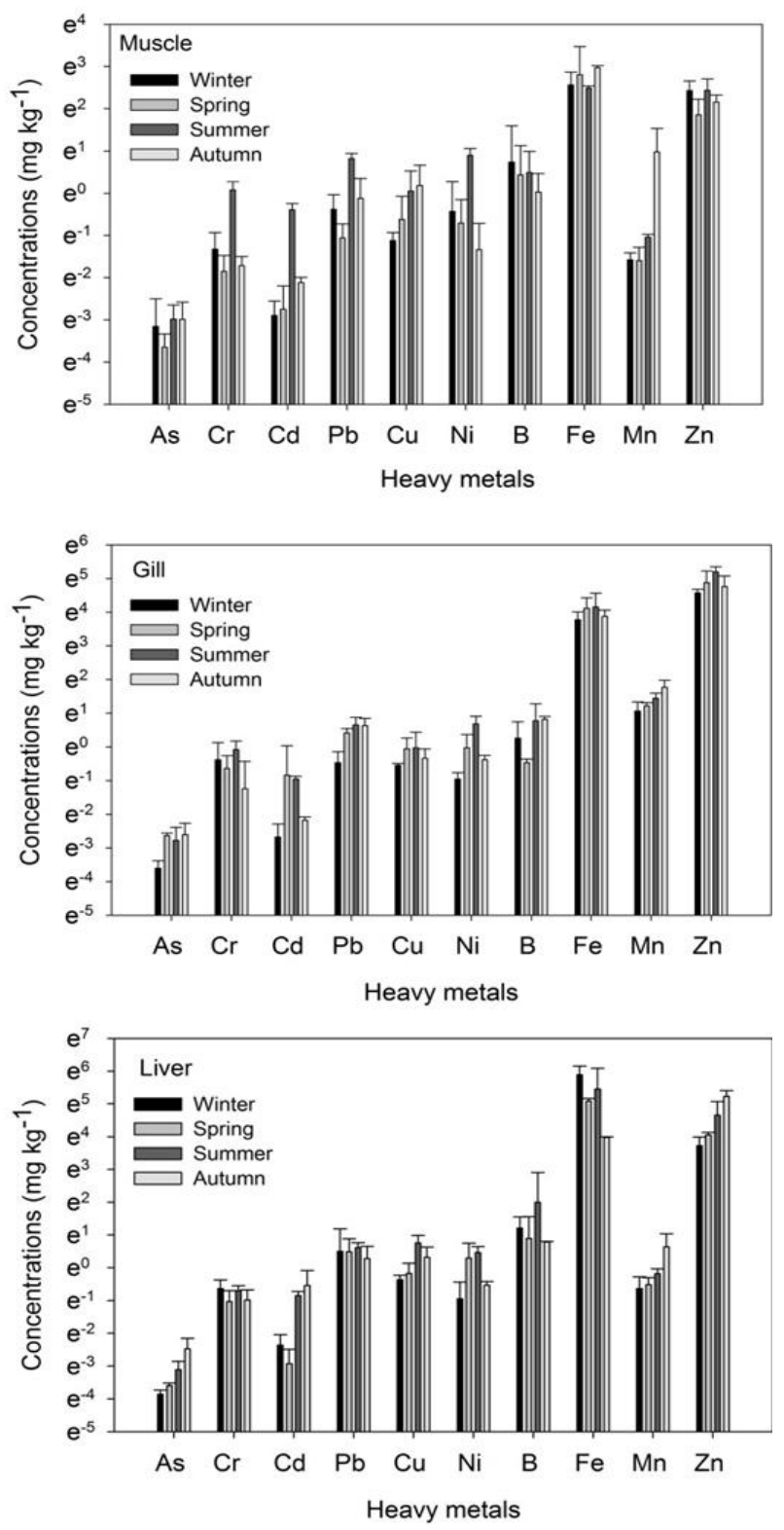

Fig. 2. Seasonal changes of metal concentrations found in tissues. 
Table 7. Seasonal trace element concentrations of treatment plant effluent.

\begin{tabular}{|c|c|c|c|c|c|}
\hline Elements & Winter $\left(\mathrm{mg} \mathrm{L}^{-1}\right)$ & Spring $\left(\mathrm{mg} \mathrm{L}^{-1}\right)$ & Summer $\left(\mathrm{mg} \mathrm{L}^{-1}\right)$ & Autumn $\left(\mathrm{mg} \mathrm{L}^{-1}\right)$ & Annual Mean $\left(\mathrm{mg} \mathrm{L}^{-1}\right)$ \\
\hline $\mathrm{As}$ & $0.0026 \pm 0.0006$ & $0.0041 \pm 0.0008$ & $0.0026 \pm 0.0001$ & $0.0037 \pm 0.0017$ & $0.0033 \pm 0.0011$ \\
\hline $\mathrm{Cr}$ & $0.0197 \pm 0.0072$ & $0.0139 \pm 0.0064$ & $0.0528 \pm 0.0117$ & $0.0536 \pm 0.0222$ & $0.035 \pm 0.0224$ \\
\hline $\mathrm{Cd}$ & $0.0046 \pm 0.0006$ & $0.0028 \pm 0.0007$ & $0.0429 \pm 0.0011$ & $0.011 \pm 0.0033$ & $0.0153 \pm 0.0168$ \\
\hline $\mathrm{Pb}$ & $0.0235 \pm 0.0045$ & $0.0180 \pm 0.0029$ & $0.0516 \pm 0.0125$ & $0.0585 \pm 0.0180$ & $0.0379 \pm 0.0206$ \\
\hline $\mathrm{Cu}$ & $0.0044 \pm 0.0039$ & $0.0073 \pm 0.0029$ & $0.0422 \pm 0.0081$ & $0.0587 \pm 0.0109$ & $0.0282 \pm 0.0247$ \\
\hline $\mathrm{Ni}$ & $0.0353 \pm 0.0069$ & $0.0390 \pm 0.0108$ & $0.0533 \pm 0.0245$ & $0.0337 \pm 0.0392$ & $0.0403 \pm 0.0229$ \\
\hline $\mathrm{B}$ & $0.3727 \pm 0.0430$ & $0.3684 \pm 0.1307$ & $0.2469 \pm 0.1683$ & $0.3690 \pm 0.0169$ & $0.3393 \pm 0.0970$ \\
\hline $\mathrm{Fe}$ & $0.2696 \pm 0.2083$ & $0.3654 \pm 0.1307$ & $0.257 \pm 0.1236$ & $0.8098 \pm 0.2879$ & $0.4254 \pm 0.2935$ \\
\hline $\mathrm{Mn}$ & $0.0881 \pm 0.0323$ & $0.0706 \pm 0.0194$ & $0.0773 \pm 0.0444$ & $0.1593 \pm 0.0556$ & $0.0988 \pm 0.0513$ \\
\hline $\mathrm{Zn}$ & $0.1174 \pm 0.0359$ & $0.0933 \pm 0.0209$ & $0.2006 \pm 0.1186$ & $0.0966 \pm 0.0291$ & $0.1270 \pm 0.0731$ \\
\hline
\end{tabular}

evaluated, the high values were found in summer and autumn months. However, $\mathrm{Cr}$ and $\mathrm{Fe}$ concentrations in liver were high in January. Seasonal changes of metal concentrations found in tissues are presented in Fig. 2.

Seasonal changes of trace element concentrations of the pool water fed by effluent from the Sewage and
Water Company of Bursa (BUSKİ) East Wastewater Treatment Plant was investigated [65]. So, similar to concentrations in fish, it was observed that trace elements were higher levels in summer and autumn months except for arsenic and boron. Seasonal trace element concentrations of treatment plant effluent are presented in Table 7.
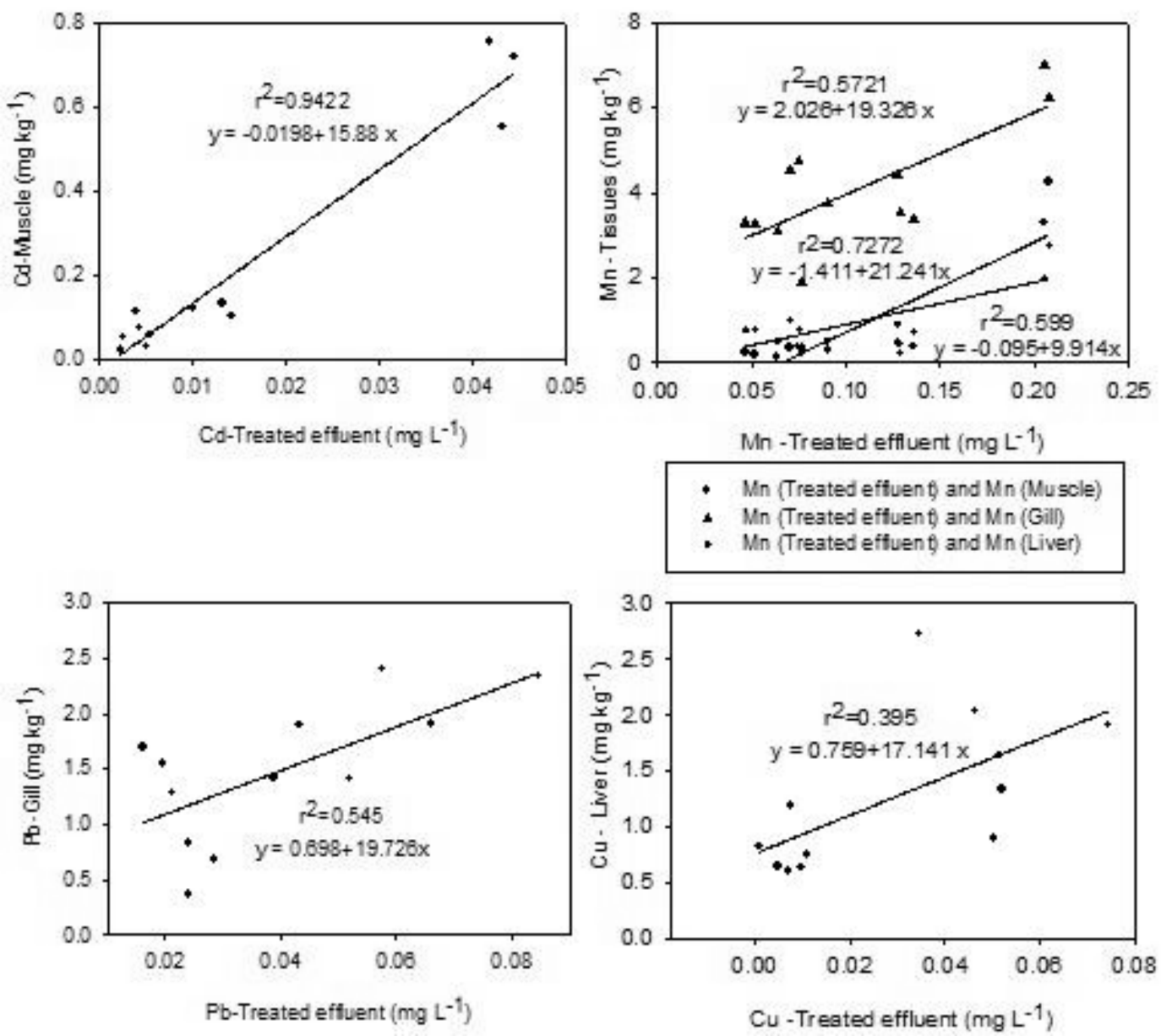

Fig. 3. Correlations between fish tissues and treated effluent. 
Correlations between effluent concentrations and concentrations in fish tissues were calculated. In addition, all of the trace element concentrations in fish tissues were found to be 10 to 1000 times higher than the values in effluent. The correlation coefficients (r) between $\mathrm{Cd}$ in effluent and $\mathrm{Cd}$ in muscle tissue, $\mathrm{Mn}$ in effluent and $\mathrm{Mn}$ in all three tissues, $\mathrm{Pb}$ in effluent and $\mathrm{Pb}$ in gills, $\mathrm{Cu}$ in effluent and $\mathrm{Cu}$ in liver were found to be statistically significant $(p<0.05)$. The correlations between fish tissues and effluent were presented in Fig. 3.

\section{Metal Bioaccumulations and Risk Assessment}

Annual and seasonal averages of transfer factors (TF), bio-concentration factors (BCF) and estimated daily intake values (EDI) were calculated by using metal concentrations in treated effluent, muscle, gill and liver tissues. In this way, bioaccumulation of metals in fish and the health risks in case of consuming were evaluated. TF, BCF, EDI, HQ values and the annual mean metal concentrations of treated effluent are given in Table 8 .

According to the calculated values, TF values of all tissues for each metal were found to be higher than 1 . We found that according to $\mathrm{BCF}$ values, only the $\mathrm{Pb}$ element was higher than U.S. EPA limit values, and the other elements were lower than the limit values.

$\mathrm{TF}$ values are more reliable than $\mathrm{BCF}$ values. Because big BCF do not indicate a hazard, it is not an intrinsic property for metals. Larger values indicate low exposure and low potential for chronic effects or secondary poisoning. There is no one value above which a hazard can be ascribed. Nearly all metals (including iron) have $\mathrm{BCF}>1000$ in natural ecosystems that are deemed to be healthy and with aqueous concentrations in the background. Extremely clean systems have even larger BCF. Metal regulation systems operate in most organisms. Metals frequently occur as charged ions in aqueous solutions and require active transport to facilitate uptake for both essential and non-essential elements. Active transport mechanisms exhibit saturable kinetics (i.e., rate limited and uptake rates decline as exposure increases). Neutral lipophilic organics uptake substances via passive diffusion across lipid bilayer. There is an inverse relationship between tissue concentration and exposure level for several metals. Hazards and the potential for chronic effects cannot be evaluated by magnitude of BCF [36]. For this reason, in this study, transfer factors of 10 metals from computed treated effluent indicated that they were all above 1, which means that bioaccumulation of all metals is a concern for potential health effects [34].

When the annual and seasonal averages of TF and $\mathrm{BCF}$ values in all three tissues were examined, $\mathrm{Zn}$ and $\mathrm{Fe}$ were the high values, and $\mathrm{B}$ and $\mathrm{Mn}$ were the low values. Annual averages of TF and BCF values of metals were in the same order. It was found as

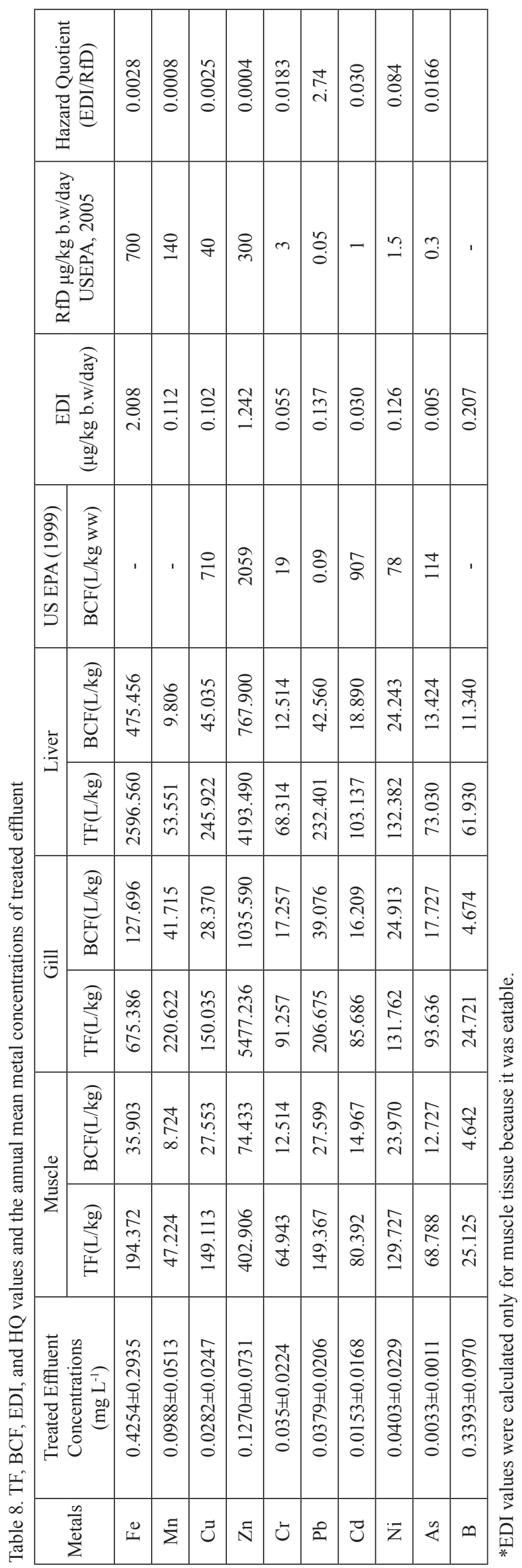


$\mathrm{Zn}>\mathrm{Fe}>\mathrm{Pb}>\mathrm{Cu}>\mathrm{Ni}>\mathrm{Cd}>\mathrm{As}>\mathrm{Cr}>\mathrm{Mn}>\mathrm{B}$ in muscle, as $\mathrm{Zn}>\mathrm{Fe}>\mathrm{Mn}>\mathrm{Pb}>\mathrm{Cu}>\mathrm{Ni}>\mathrm{As}>\mathrm{Cr}>\mathrm{Cd}>\mathrm{B}$ in gill, and as $\mathrm{Zn}>\mathrm{Fe}>\mathrm{Cu}>\mathrm{Pb}>\mathrm{Ni}>\mathrm{Cd}>\mathrm{As}>\mathrm{Cr}>\mathrm{B}>\mathrm{Mn}$ in liver. When the seasonal changes in $\mathrm{TF}$ and $\mathrm{BCF}$ values were compared, some similarities were observed. Fe, $\mathrm{Zn}$ and $\mathrm{Cu}$ elements were found to be higher in magnitude order. In both factors, $\mathrm{Cr}, \mathrm{Pb}, \mathrm{Ni}$ and $\mathrm{B}$ elements in muscle tissue were found to be higher in summer months, $\mathrm{Cd}$ was higher in spring, Mn was higher in autumn and $\mathrm{Zn}$ was higher in winter. However, BCF values of $\mathrm{As}, \mathrm{Fe}$ and $\mathrm{Cu}$ were higher in autumn, TF values of $\mathrm{As}$ and $\mathrm{Fe}$ were higher in summer months, and TF value of $\mathrm{Cu}$ was higher in spring. For both factors, $\mathrm{Cr}, \mathrm{Cd}$ and $\mathrm{Zn}$ values in gill tissues were found to be higher in spring, while $\mathrm{Ni}$ and $\mathrm{Fe}$ were higher in summer and $\mathrm{Cu}$ was found to be higher in winter. However, while BCF values of As, $\mathrm{Pb}, \mathrm{B}$ and $\mathrm{Mn}$ were higher in autumn, TF values of As, $\mathrm{B}$ and $\mathrm{Mn}$ were higher in summer months, and TF value of $\mathrm{Pb}$ was higher in spring. For both factors, $\mathrm{As}, \mathrm{Cd}, \mathrm{Mn}$ and $\mathrm{Zn}$ values in liver tissues were found to be higher in autumn, while $\mathrm{Cr}, \mathrm{Cu}$ and and $\mathrm{Fe}$ were higher in winter and $\mathrm{Pb}$ and $\mathrm{Ni}$ were found to be higher in spring. However, TF value of B element was higher in summer; $\mathrm{BCF}$ value was higher in autumn. In Figure 4, Seasonal changes of $\mathrm{TF}$ values determined for muscle, gill and liver tissues are presented.

Although the magnitude order of annual averages of metal concentrations found in fish tissues were different, according to the standards of international institutions (FAO and WHO) the same elements in all three tissue were found to be high ( $\mathrm{Mn}, \mathrm{Zn}, \mathrm{Cr}, \mathrm{Cd}$ and $\mathrm{Pb}$ ) and were low $(\mathrm{Cu}$ and $\mathrm{Ni})$. In all three tissues, Ni element was higher than Carassius gibelio species living in different areas, and $\mathrm{Zn}, \mathrm{Cr}$ and $\mathrm{Pb}$ were higher than the other fish species. When the magnitude order of concentrations in tissues and the magnitude order of TF and $\mathrm{BCF}$ of bioaccumulation factors were compared, although similar, some differences were observed. While the concentrations of $\mathrm{B}$ and $\mathrm{Mn}$ elements were found to be high in all tissues, magnitude orders of this element's bioaccumulation factors were lower, and while the concentrations of $\mathrm{Cd}$ and As elements were lower, their biological accumulations were found to be higher in all tissues. However, according to $\mathrm{TF}$ values, all elements bio-accumulated in all three tissues. When the seasonal changes in TF and BCF values were compared, $\mathrm{Fe}, \mathrm{Zn}$ and $\mathrm{Cu}$ elements were found at the highest values in all three tissues. In general, concentrations in the tissues and effluent water were found to be higher in summer and autumn. However, seasonal changes of bioaccumulation factors were found to be different.

Seasonal changes of metal concentrations in tissues and bioaccumulation factors were found to be different. Except for $\mathrm{B}$ and $\mathrm{Fe}$, while other element concentrations were found to be higher in all tissues in summer, TF and $\mathrm{BCF}$ values were found to be higher in different seasons. Similar to concentrations in fish other than As and B, the elements in effluent water were found to be higher in summer and autumn. However, the correlations between
$\mathrm{Cd}, \mathrm{Mn}, \mathrm{Pb}$ and $\mathrm{Cu}$ concentrations in effluent and in fish tissues were found to be statistically significant. It was considered that these elements caused bioaccumulation because of effluent. In terms of other elements, there was a difference between seasonal changes of biological accumulation factors and seasonal differences of metal concentrations in the effluent. For this reason, the bioaccumulations in the fish were thought to be influential by the baits outside of the water and the sediment layer of the feeding pool.

As was seen in Table 8, EDI and HQ values that were calculated by using annual average concentrations had carcinogenic risk only in terms of $\mathrm{Pb}$ and did not have any carcinogenic risk in terms of other metals. HQ value of $\mathrm{Pb}$ was found to be greater than 1 . In addition to being carcinogenic, the lead element is poisonous and causes brain damage because it imitates the metabolic behavior of calcium in many ways and prevents many enzyme systems from functioning [61].

\section{Conclusions}

The treated effluent water used in this research was considered as partially available for aquaculture and completely available for irrigation water. Metal concentrations in the fish were found to be higher than the standards, and their seasonal changes (higher in summer and autumn) were statistically significant. While the concentrations were higher in liver and gill, less metal accumulation was observed in muscle. However, all metals examined ( $\mathrm{Fe}, \mathrm{Mn}, \mathrm{Cu}, \mathrm{Ni}, \mathrm{Zn}, \mathrm{Cr}$, $\mathrm{Pb}, \mathrm{Cd}, \mathrm{As}$ and B) were biologically accumulated in each of the three tissues. Because the correlations between $\mathrm{Cd}, \mathrm{Mn}, \mathrm{Pb}$ and $\mathrm{Cu}$ in tissues and these elements in effluent water were significant, it was considered that $\mathrm{Cd}, \mathrm{Mn}, \mathrm{Pb}$ and $\mathrm{Cu}$ caused bioaccumulation stemming from treated effluent water, and other metals might have caused bioaccumulation stemming from baits and sediment layer in the feeding pool. Concentrations of $\mathrm{Cd}, \mathrm{Mn}$ and $\mathrm{Pb}$ in each of three tissues that had high correlation with treated effluent water were found to be higher than the international standards. In addition, according to calculated HQ values, $\mathrm{Pb}$ element in muscle had carcinogenic risk and $\mathrm{BCF}$ value of only $\mathrm{Pb}$ among all elements was higher than limit values. In addition, all metals (except $\mathrm{As}$ and $\mathrm{Cu}$ ) in muscle were higher than Carassius gibelio species living in different surface water and other fish species. Therefore, the fish were not available for human consumption and animal feed. The fact that the most dangerous metals, $\mathrm{Pb}$ and $\mathrm{Cd}$, were higher than the international standards in all three tissues and that the concentration differences between tissues were not statistically significant indicated that the use of the part of the fish (muscle) and other organs as animal bait was not appropriate. This research proved that treated effluent water might cause biological accumulation even if it was suitable for aquaculture. For this reason, attempts should be retried by cultivating 
the fish in the treated water using "advanced treatment" methods. Add to this, in later studies investigating concentrations in baits and sediment layers would be useful. In addition, comparative studies of different fish species and different micro-pollutants would provide more comprehensive information on the use of treated wastewater in aquaculture. Also, there are no guideline values or provisional limits for metal intake (g/day/body weight), the results obtained in this study could be used to derive such guideline values. However, this needs to be further examined in future studies.

\section{References}

1. SCHEUMANN W., KIBAROGLU A., KRAMER A. Turkey's Water Policy National Frameworks and International Cooperation, Springer, 2011

2. GISECKE U., HEILAND S., MILLIION A., JUNGE R. Urban Aquaculture, Deutsche National Bibliothek, Berlin, 2014.

3. UN. Wastewater the Untapped Resource, the United Nations World Water Development Report 2017.

4. EDWARDS P., PULLIN, R.S.V. Wastewater-Fed Aquaculture Systems: Status and Prospects, NAGA, 19 (1), 33, 1996.

5. KATIP A., KARAER F., BAŞKAYA H.S., İLERİ S., SARMAŞIK S. Fraction Distribution and Risk Assessment of Heavy Metals and Trace Elements in Sediments of Lake Uluabat. Environmental Monitoring and Assessment 184 (9), 5399, 2012

6. GIRARD J.J. Feasibility of Wastewater Reuse for Fish Production in Small Communities in a Developing World Setting, Master of Science, University of South Florida, 112, 2011.

7. MANDAL R.N., CHAKRABARTI P.P., PAUL B.N., CHATTOPADHYAY D.D., DAS A., HUSSAN A., JAYASANKAR P. Recycling of Sewage in Aquaculture: Decadal Technical Advancement, In: Jana B., Mandal R., Jayasankar P. (eds) Wastewater Management Through Aquaculture. Springer, Singapore, 2018

8. LAM S., NGUYEN-VIET H., TUYET-HANH T.T., NGUYEN-MAİ H., HARPER S. Evidence for Public Health Risks of Wastewater and Excreta Management Practices in Southeast Asia: A Scoping Review, International Journal of Environmental Research and Public Health, 12, 12863, 2015.

9. DARKO G., AZANU D., LOGO N.K. Accumulation of toxic metals in fish raised from sewage-fed aquaculture and estimated health risks associated with their consumption, Cogent Environmental Science, 2, 1190116, 2016.

10. JANA R.B.B., MANDAL R.N., JAYASANKAR P. Wastewater Management Through Aquaculture, Springer Nature Singapore PTE Ltd. 2018.

11. ÖZULUĞ M., SAÇ G., GAYGUSUZ Ö. İstilacı Özellikteki Gambusia holbrooki, Carassius gibelio ve Pseudorasbora parva (Teleostei) Türleri İçin Türkiye' den Yeni Yayılım Alanları. Su Ürünleri Dergisi, 8, 1, 2013.

12. APHA AWWA Standard Methods for the Examination of Water and Wastewater. American Public Heallth Association, $23^{\text {rd }}$ Edition. Washington DC USA, 2017.

13. BENZER S., ARSLAN H., UZEL N., GÜL A. YILMAZ M. Concentrations of metals in water, sediment and tissues of Cyprinus carpio L., 1758 from Mogan Lake (Turkey), Iranian Journal of Fisheries Sciences, 12 (1) 45, 2013.

14. UYSAL K., KÖSE E., BÜLBÜL M., DÖNMEZ M., ERDOĞAN Y., KOYUN M., ÖMEROĞLU C.., ÖZMAL F. The comparison of heavy metal accumulation ratios of some fish species in Enne Dame Lake (Kütahya/Turkey). Environ Monit Assess, 157, 355, 2009.

15. TEKIN-ÖZAN S., KIR İ. Concentrations of Some Heavy Metals in Organs of Two Fish Species from the Beysehir Lake, Turkey. Fresen. Environ. Bull. 15, 530, 2006.

16. TEKIN-ÖZAN S., KIR İ. Seasonal Variations of Heavy Metals in Some Organs of Carp (Cprinus carpio L. 1758) from Beyşehir Lake (Turkey). Environmental Monitoring and Assessment, 138, 201, 2008.

17. MOHAMMED E., MOHAMMED T., MOHAMMED A. Optimization of an acid digestion procedure for the determination of $\mathrm{Hg}, \mathrm{As}, \mathrm{Sb}, \mathrm{Pb}$ and $\mathrm{Cd}$ in fish muscle tissue, MethodsX, 4, 513, 2017.

18. ERDOĞAN Z., TORCU KOÇ H., GÜNGÖR S., ULUNEHIR G. Age, growth and reproductive properties of an invasive species Carassius gibelio (Bloch, 1782) (Cyprinidae) in the Ikizcetepeler Dam Lake (Balikesir), Turkey, Periodicum Biologorum, 116 (3), 285, 2014.

19. TARKAN A.S. Yabancı Tatlısu Balıklarının Dünyada ve Türkiye'de Giriş Yolları, Etkileri ve Bunlardan Korunma Yöntemleri. Su Ürünleri Dergisi 28, 63, 2013.

20. ANONYMOUS. Aquaculture Regulations-Acceptable Values for receiving environment. Official Gazette. Date 10.03.1995 Issue 22223, 1995.

21. ANONYMOUS. National Standard of the People's Republic of China waste water discard standards. GB 8978, 1996

22. ANONYMOUS. Aquaculture Law and Regulation, Ministry of Agriculture and Rural Affairs. Ankara 63, 2002.

23. ANONYMOUS. Notification of Wastewater Treatment Plant Technical Procedures - Criteria for the Use of Wastewater as Irrigation Water. Official newspaper. Date 20 Mart 2010 Issue: 27527, 2010.

24. WHO. Guidelines for Drinking-Water Quality, $4^{\text {th }}$ Edition, inc. Addendum, 2017.

25. EU. The Drinking Water Directive Directive 2015/83/EC 1787/83/EC.2015.

26. USEPA. National Recommended Water Quality CriteriaCorrection EPA 4304T, 2009.

27. TSE. Turkish Standardization Institute TS266 Standards Water for Human Consumption (Turkish standards) Rep: 25730 Ministry of Health, Ankara. 2005.

28. FAO. Food and Agriculture Organization, Compilation of legal limits for hazardous substances in fish and fishery products. FAO Fishery Circular 464, 5, 1983.

29. FAO/WHO. Evaluation of certain food additives and the contaminants mercury, lead and cadmium. WHO Technical Report, Series No. 505, 1989.

30. EL-MOSELHY K.M., OTHMAN A.I., EL-AZEM H.A., METWALLY M.E.A. Bioaccumulation of heavy metals in some tissues of fish in the Red Sea, Egypt. Egyptian Journal of Basic and Applied Sciences, I, 97, 2014.

31. AKAN J.C., MOHMOUD S., YIKALA B.S., OGUGBUAJA V.O. Bioaccumulation of Some Heavy Metals in Fish Samples from River Benue in Vinikilang, Adamawa State, Nigeria. American Journal of Analytical Chemistry, 3, 727, 2012.

32. MAFF. Ministry of Agriculture, Fisheries and Food, Monitoring and surveillance of non-radioactive 
contaminants in the aquatic environment and activities regulating the disposal of wastes at sea, 1997. In Aquatic Environment Monitoring Report No. 52. Center for Environment, Fisheries and Aquaculture Science, Lowestoft, UK. 2000.

33. TFC. Turkish Food Codes, - Maximum Limits of Contaminants in Foodstuffs. Official Gazette. Date 29.12.2011, Issue: 28157, 2011.

34. ABDEL-BAKI A.S., DKHIL M.A., AL-QURAISHY $\mathrm{S}$. Bioaccumulation of some heavy metals in tilapia fish relevant to their concentration in water and sediment of Wadi Hanifah, Saudi Arabia, African Journal of Biotechnology, 10 (13), 2541, 2011.

35. USEPA. 1999b. Screening Level Ecological Risk Assessment Protocol for Hazardous Waste Combustion Facilities. United States Environmental Protection Agency EPA530-D-99-001C. 1999.

36. OECD. Bioaccumulation of Metal Substances by Aquatic Organisms Part 1. OECD Meeting, Paris, September 7, 2011.

37. ONSAINT S., KE C., WANG K.J., WANG W.X. Trace elements in two marine fish cultured in fish cultured in fish cages in Fujian province, China. Environ. Pollut. 15, 1334, 2010.

38. EKEANYANWU R.C., NWOKEDI C.L., NOAH U.T. Monitoring of Metals in Tilapia Nilotica Tissues, Bottom Sediments and Water from Nworie River and Oguta Lake in Imo State, Nigeria. African Journal of Environmental Science and Technology, 9 (8), 682, 2015.

39. SARIÖZKAN S. Türkiye'de Balıkçılık Sektörü ve Ekonomisi. Turkish Journal of Aquatic Sciences 31 (1), 15, 2016.

40. MOL S., KARAKULAK F.S., ULUSOY S. Assessment of Potential Health Risks of Heavy Metals to the General Public in Turkey via Consumption of Red Mullet, Whiting, Turbot from the Southwest Black Sea, Turkish Journal of Fisheries and Aquatic Sciences 17, 1135, 2017.

41. MINITAB. Minitab 18 Statistical Analysis Software. 2017.

42. KUMAR B., MUKHERJEE D.P., KUMAR S., MISHRA M., PRAKASH D., SINGH K., SHARMA C.S. Bioaccumulation of Heavy Metals in Muscle Tissue of Fishes from Selected Aquaculture Ponds in East Kolkata Wetlands. Annals of Biological Research, 2 (5), 125, 2011.

43. USFDA US Food and Drug Administration,Food and drug administration. Guidance document for arsenic in shellfish. Washington DC: DHHS/PHS/FDA/CFSAN/ Office of Seafood. 1993.

44. EMİROĞLU Ö., ÇİÇEK A., ARSLAN N., AKSAN S., RÜZGAR M. Boron Concentration in Water, Sediment and Different Organisms around Large Borate Deposits of Turkey. Bull Environ Contam Toxicol 84, 427, 2010.

45. ÖZPARLAK H., ARSLAN G., ARSLAN E. Determination of Some Metal Levels in Muscle Tissue of Nine Fish Species from Beyşehir Lake, Turkey. Turkish Journal of Fisheries and Aquatic Sciences, 12, 761, 2012.

46. KÖSE E., UYSAL K. The Comparison of Heavy Accumulation Ratios in Muscle, Skin and Gill of NonMaturated Common Carp (Cyprinus carpio L. 1758) (in Turkish with English abstract). Dumlupınar Üniversitesi Fen Bilimleri Enstitüsü Dergisi 17, 19, 2008.

47. MILOS`KOVIC A., BRANKOVIĆ S., SIMİ́ V., KOVAČEVIĆ S., ĆİRKOVIĆ M., MANOJLOVIĆC D. The Accumulation and Distribution of Metals in Water, Sediment, Aquatic Macrophytes and Fishes of the Gruza Reservoir, Serbia. Bull Environ Contam Toxicol, 90, 563, 2013.
48. SKORIC S., VISNJIC-JETFIC Z., JARIC I., DJIKANOVIC V., MICKOVIC B., NIKCEVIC M., LENHARDT M. Accumulation of 20 elements in great cormorant (Phalacrocorax carbo) and its main prey, common carp (Cyprinus carpio) and Prussian carp (Carassius gibelio). Ecotoxicology and Environmental Safety 80, 244, 2012.

49. UYSAL K., ATALAY M.A. DPÜ Göleti'nde ekstansif yetiştiriciliği yapılan aynalı sazanların (Cyprinus carpio) gelişimi ve ağır metal akümülasyon oranlarının değerlendirilmesi. Türk Sucul Yaşam Dergisi (Turkish Journal of Aquatic Life) Ulusal Su Günleri 2007 Sempozyum Özel Sayıs1, 5-8, 663, 2007.

50. IRAİDA G.S., KHLOPOVA A.V., CHUKHLEBOVA L.M. Assessment of the State of the Gibel Carp Carassius auratus gibelio in the Amur River Basin: Heavy-Metal and Arsenic Concentrations and Histopathology of Internal Organs. Arch Environ Contam Toxic 62, 465, 2012.

51. Çİ̧̧EK A., EMİROĞLU Ö., ARSLAN N. Heavy metal concentration in fish of Lake Manyas. 13. World Lake Conference, 1-5 Nov, Wuhan, China, Abstract 535, 2009.

52. EBRAHIMPOUR M., POURKHABBAZ A., BARAMAKI R., BABAEI H., REZAEI M. Bioaccumulation of Heavy Metals in Freshwater Fish Species, Anzali, Iran. Bull Environ Contam Toxicol 87, 386, 2011.

53. WANG X., CHU Z., ZHA F., LIU S, LIU G., DONG Z. Determination of Heavy Metals in Water and Tissues of Crucian Carp (Carassius auratus Gibelio) Collected from Subsidence Pools in Huainan Coal Fields (China). Analytical Letters 48, 861, 2015.

54. YABANLI M., YOZUKMAZ A., SELF. Bioaccumulation of Heavy Metals in Tissues of the Gibel Carp Carassius gibelio: Example of Marmara Lake, Turkey. Russian Journal of Biological Invasions, 5 (3), 217, 2014.

55. SAPOZHNIKOVA Y., ZUBCOV N., HUNGERFORD S., ROY L.A., BOICENCO N., ZUBCOV E., SCHLENK D. Evaluation of pesticides and metals in fish of the Dniester River, Moldova. Chemosphere 60,196, 2005.

56. MAZEJ Z., AL SAYEGH-PETKOVŠEK S., POKORNY B. Heavy metal concentrations in food chain of Lake Velenjsko jezero, Slovenia: An artificial lake from mining. Arch. Environ. Contam. Toxicol 58, 998, DOI: 10.1007/ s00244-009-9417, 2010.

57. ÇİÇEK A., ARSLAN N., KOÇ B., MALKOÇ S., EMİROĞLU Ö. Determination of lead levels in Lake water, sediment, Meiobentos, (Chironomidae) and tree fish species from Lake Uluabat (A Ramsar Site in Turkey), Sengupta $M$ and Dalwani R. (Editors) Proceeding of Taal2007. The $12^{\text {th }}$ World Lake Conference: $257,2008$.

58. ÖZTURK, M., OZOZEN, G., MINARECI, O., MINARECI, E. Determination of heavy metals in fish, water and sediments of Avsar Dam Lake in Turkey. Iranian Journal of Environmental Health Science and Engineering, 6, 73, 2009.

59. HAS-SCHO“N E., BOGUT I., RAJKOVIC V., BOGUT S., $C^{`}{ }^{\wedge} C^{`} \dot{I}^{\prime} C^{\prime}$ M., HORVATİC J. Heavy Metal Distribution in Tissues of Six Fish Species Included in Human Diet, Inhabiting Freshwaters of the Nature Park "Hutovo Blato" (Bosnia and Herzegovina). Arch Environ Contam Toxicol, 54, 75, 2008.

60. ATSDR. Agency for Toxic Substances and Disease Registry Toxic Substances Portal. ToxGuideTM for Cadmium $\mathrm{Cd}$ and $\mathrm{Pb}, 2018$.

61. DÜNDAR M.Ş., ALTUNDAĞ H., KAYGALDURAK S., ŞAR V., ACAR A. Çeşitli endüstriyel atık sularda 
ağır metal düzeylerinin belirlenmesi. SAÜ. Fen Bilimleri Dergisi 16, 6, 2012.

62. ELGENDY, M.Y., ABUMOURAD, I.K., ELSAYED, S., ALI, M., SOLIMAN, W.S.E., IBRAHIM, T.B.E., ABBAS, W.T. Health Status and Genotoxic Effects of Metal Pollution in Tilapia zillii and Solea vulgaris from Polluted Aquatic Habitats, International Journal of Zoological Research, 13 (2), 54, 2017.

63. JAISHANKAR M., TSETEN T., ANBALAGAN N., MATHEW B.B., BEEREGOWDA K.N. Toxicity, mechanism and health effects of some heavy metals, Interdisciplinary Toxicology, 7 (2), 60, 2014.
64. FRANCESCA S.S. Aquatic pollution and biological monitoring of the marine environment: toxicology, histopathology and ecological risk of selected fish species, Universita Deglı Stud1 D1 Milano, Facolta di Medicina Veterinaria Dipartimento di Scienze veterinarie e Sanita pubblica, PhD Course of Veterinary Hygiene and Animal Pathology XXVIII cycle, 2015.

65. SWCB, Sewage and Water Company of Bursa (SWCB) East Wastewater Treatment Plant Annual Raports. 2011. 